\title{
Minimal self-immolative probe for multimodal fluoride detection.
}

\author{
Dipartimento di Science Chimiche, Università di Padova, \\ via Marzolo 1, I-35131 Padova (Italy) \\ Luca Gabrielli*, Fabrizio Mancin
}

\section{Supporting Information}

\section{Table of Contents}

1. ${ }^{1} \mathrm{H}$ and ${ }^{19} \mathrm{~F}$ NMR experiments.

S2

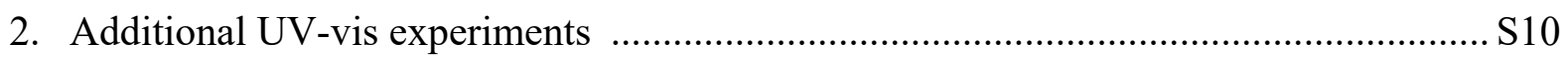

3. ${ }^{1} \mathrm{H},{ }^{13} \mathrm{C},{ }^{19} \mathrm{~F},{ }^{29} \mathrm{Si}-\mathrm{NMR}$ and MS spectra of the synthesized compounds....................... S16 


\section{1. ${ }^{1} \mathrm{H}$ and ${ }^{19} \mathrm{~F}$ NMR experiments.}

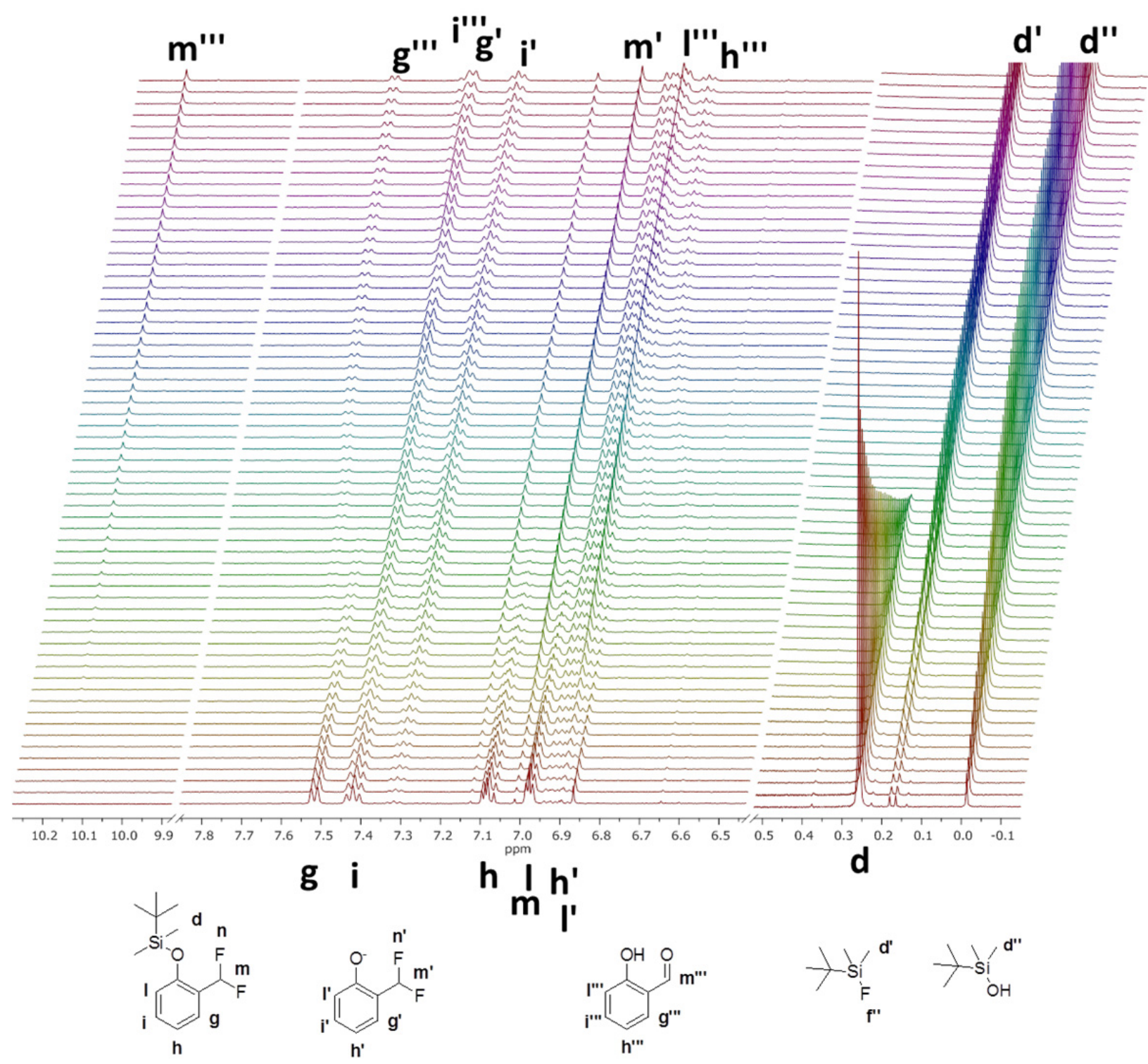

Figure 1. ${ }^{1} \mathrm{H}-\mathrm{NMR}$ kinetic experiment. Probe $1500 \mu \mathrm{M}$, TBAF $25 \mu \mathrm{M} . \mathrm{d} 1=5 \mathrm{~s} ; 64$ spectra, spectrum acquisition every $20 \mathrm{~min}$ (12 min acquisition, 8 min delay). 


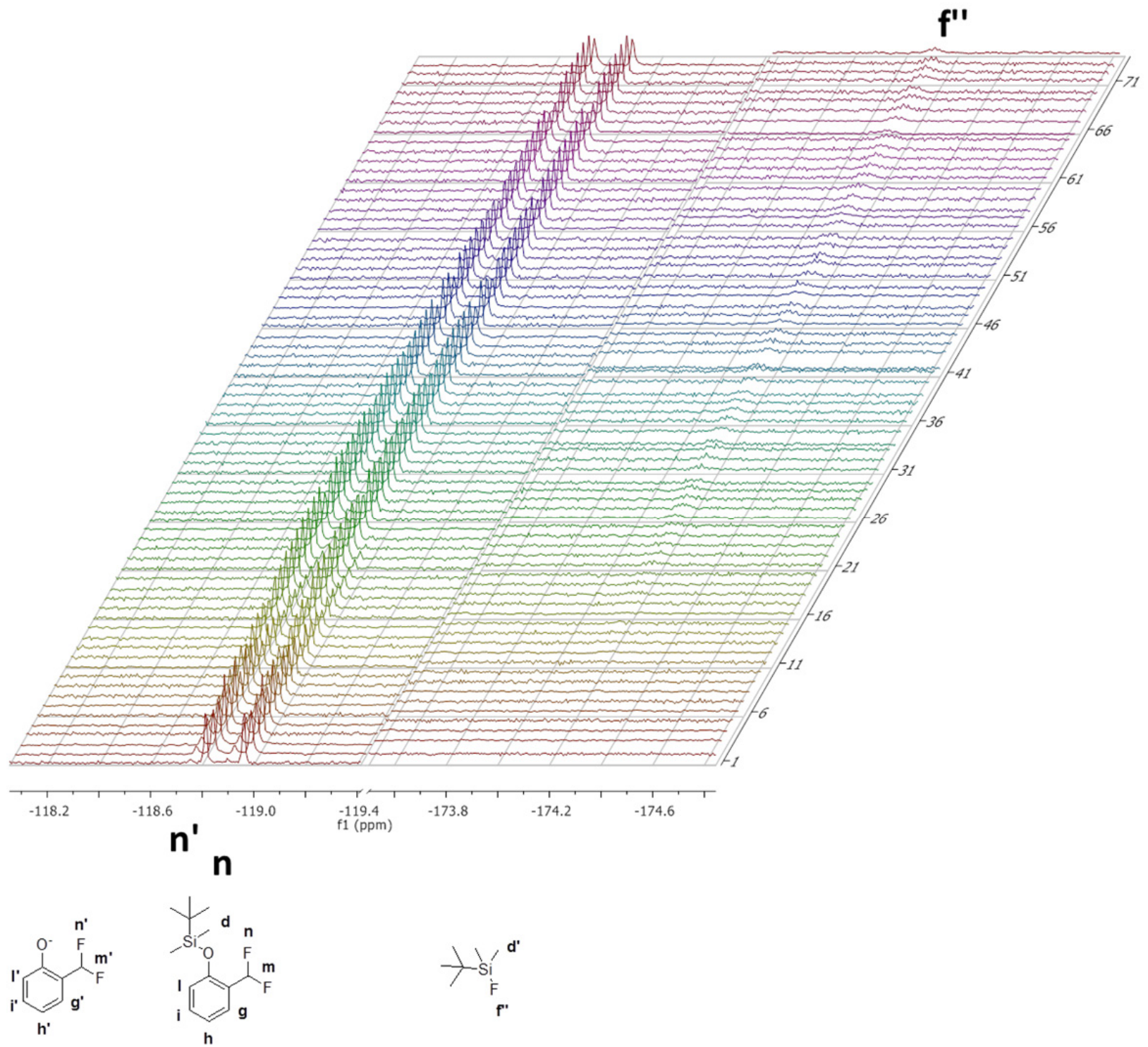

Figure 2. ${ }^{19}$ F-NMR kinetic experiment. Probe $2500 \mu \mathrm{M}$, TBAF $25 \mu \mathrm{M}$. scan= 256; 74 spectra, spectrum acquisition every $20 \mathrm{~min}$ ( 9 min acquisition, 11 min delay). 


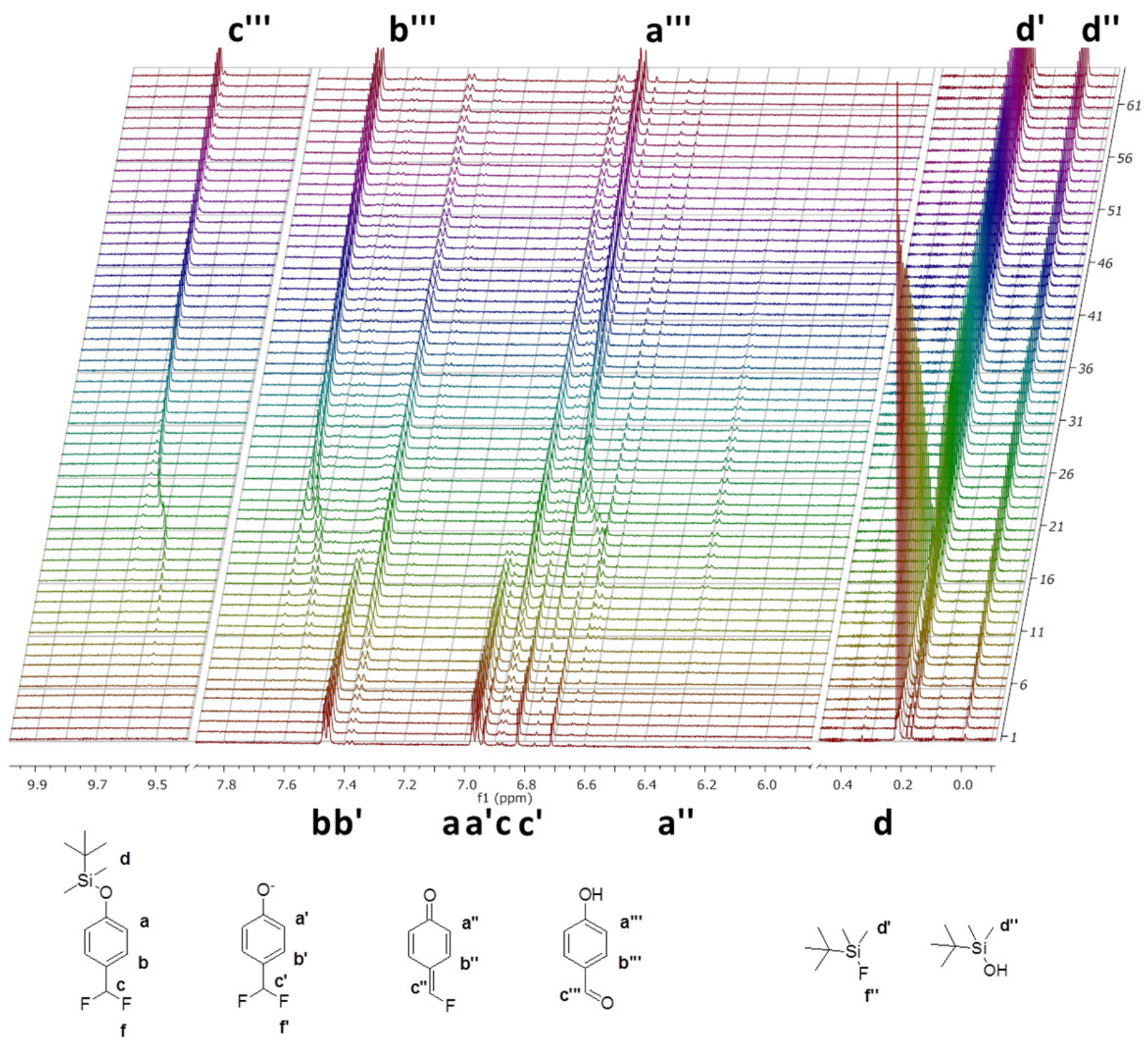

Figure 3. ${ }^{1} \mathrm{H}-\mathrm{NMR}$ kinetic experiment. Probe $1500 \mu \mathrm{M}$, TBAF $25 \mu \mathrm{M} . \mathrm{d} 1=5 \mathrm{~s} ; 64$ spectra, spectrum acquisition every $20 \mathrm{~min}$ (12 min acquisition, 8 min delay). 


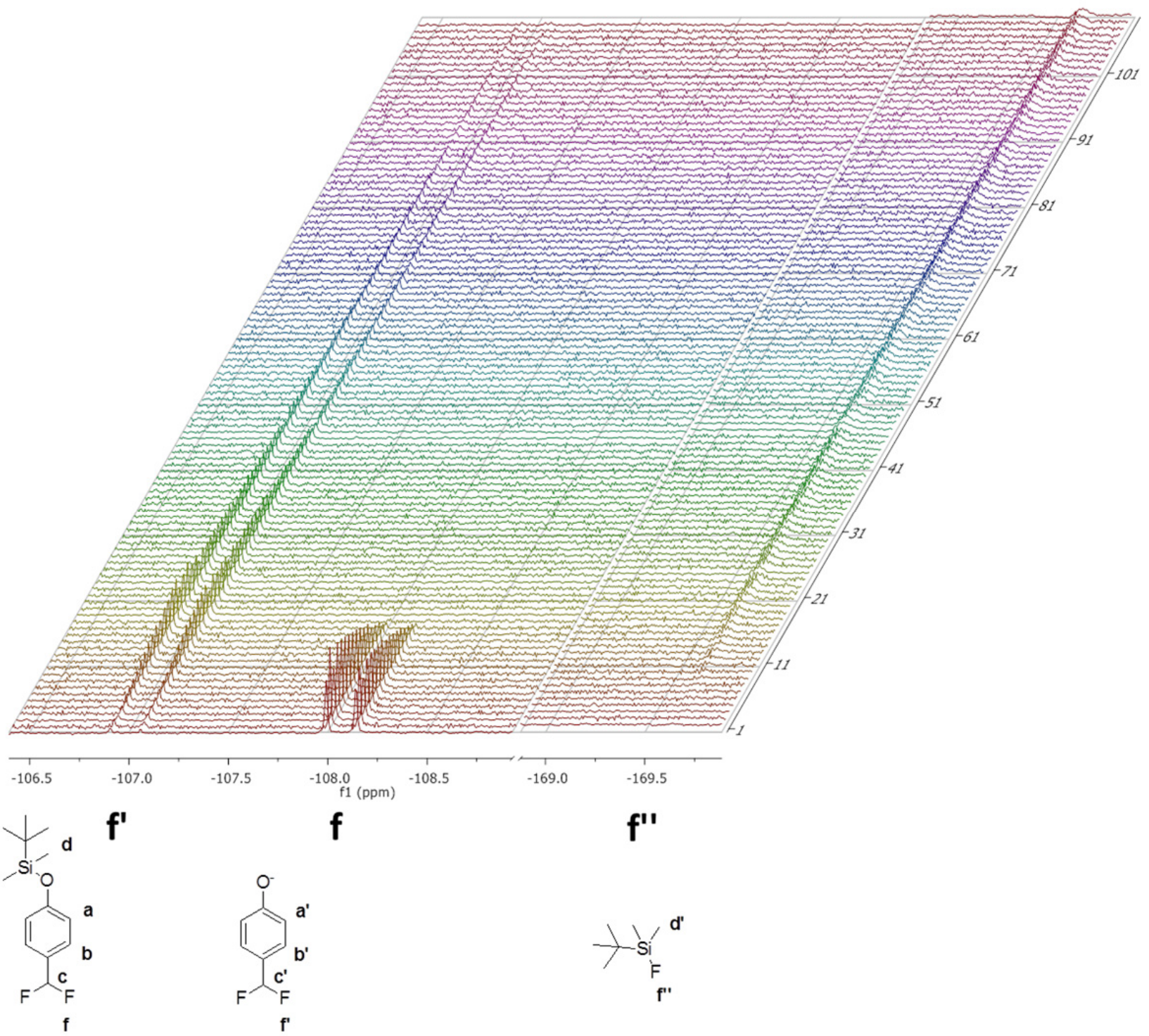

Figure 4. ${ }^{19}$ F-NMR kinetic experiment. Probe $2500 \mu \mathrm{M}$, TBAF $25 \mu \mathrm{M}$. scan= 256; 74 spectra, spectrum acquisition every $20 \mathrm{~min}$ ( 9 min acquisition, 11 min delay). 


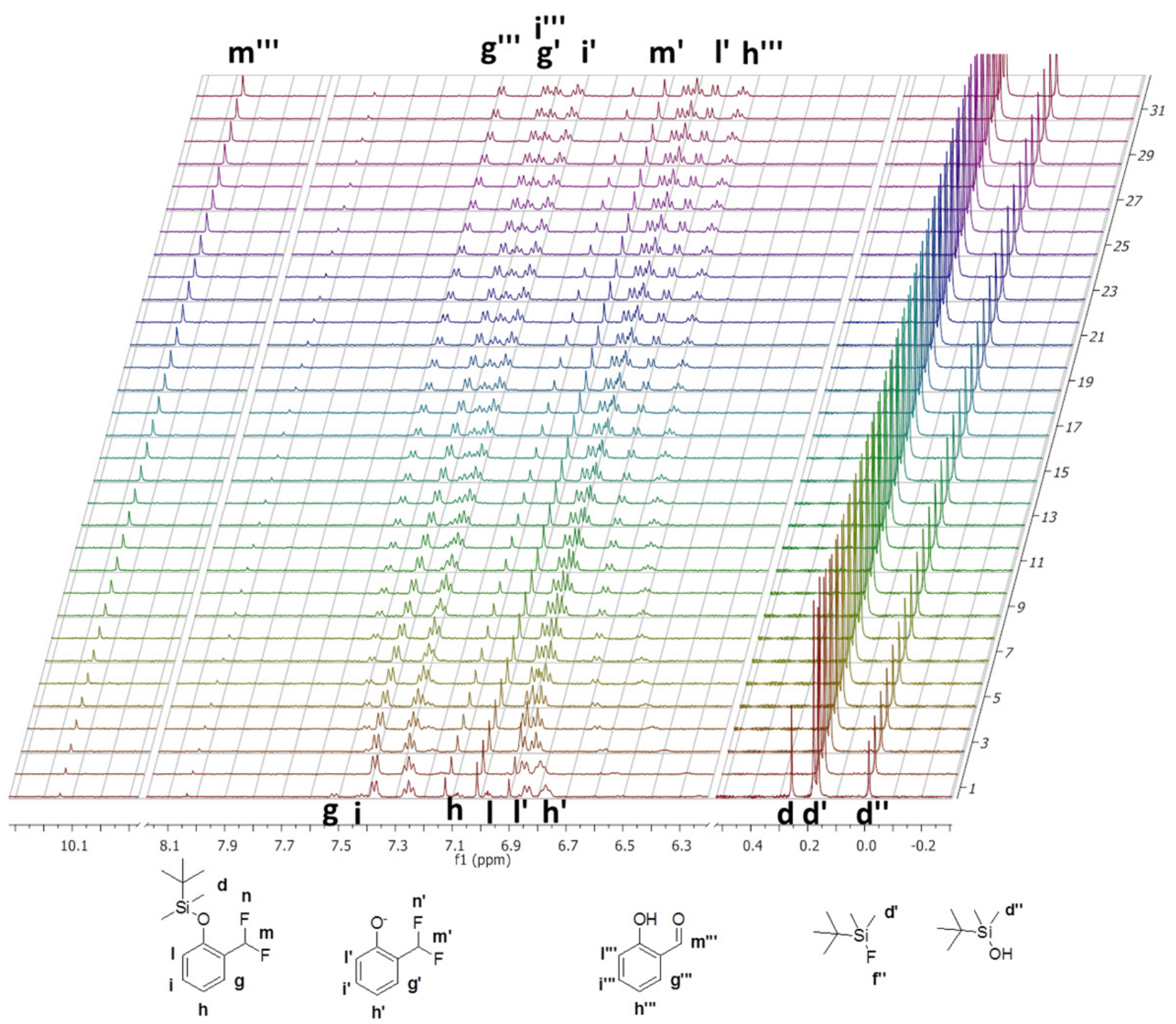

Figure 5. ${ }^{1} \mathrm{H}-\mathrm{NMR}$ kinetic experiment. Probe $1500 \mu \mathrm{M}$, TBAF $250 \mu \mathrm{M}$. d1 $=5 \mathrm{~s} ; 64$ spectra, spectrum acquisition every 20 min (12 min acquisition, 8 min delay). 


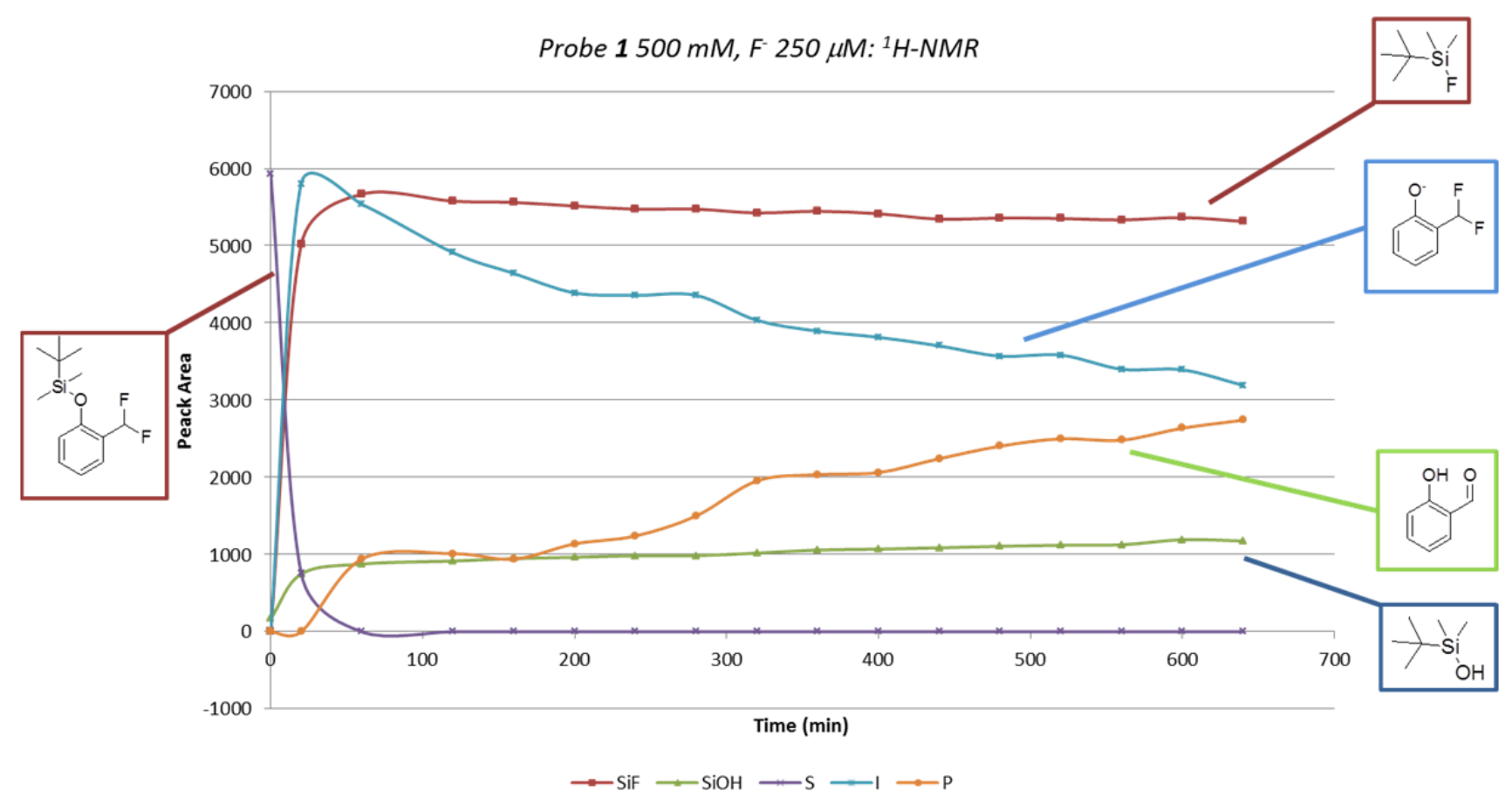

Figure 6. ${ }^{1} \mathrm{H}-\mathrm{NMR}$ kinetic study (Figure 5$)$ of probe 1. $(500 \mu \mathrm{M})$ reaction with TBAF $(250 \mu \mathrm{M})$. The normalized area of characteristic compound's peaks is plotted $v s$ reaction time. 


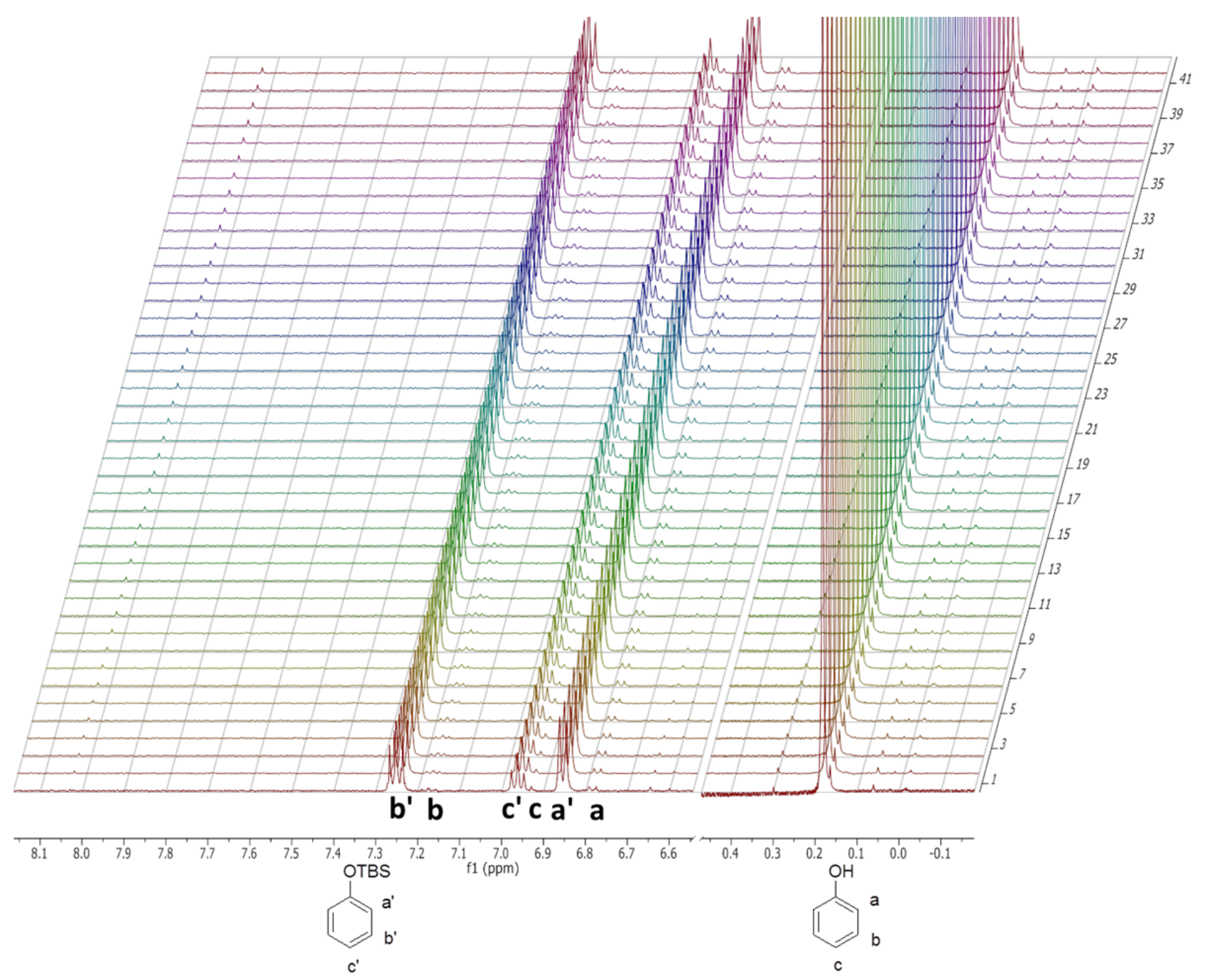

Figure 7. ${ }^{1} \mathrm{H}-\mathrm{NMR}$ kinetic experiment. Compound $3500 \mu \mathrm{M}$, TBAF $25 \mu \mathrm{M}$. d1 $=5 \mathrm{~s} ; 64$ spectra, spectrum acquisition every $20 \mathrm{~min}$ (12 min acquisition, 8 min delay). 


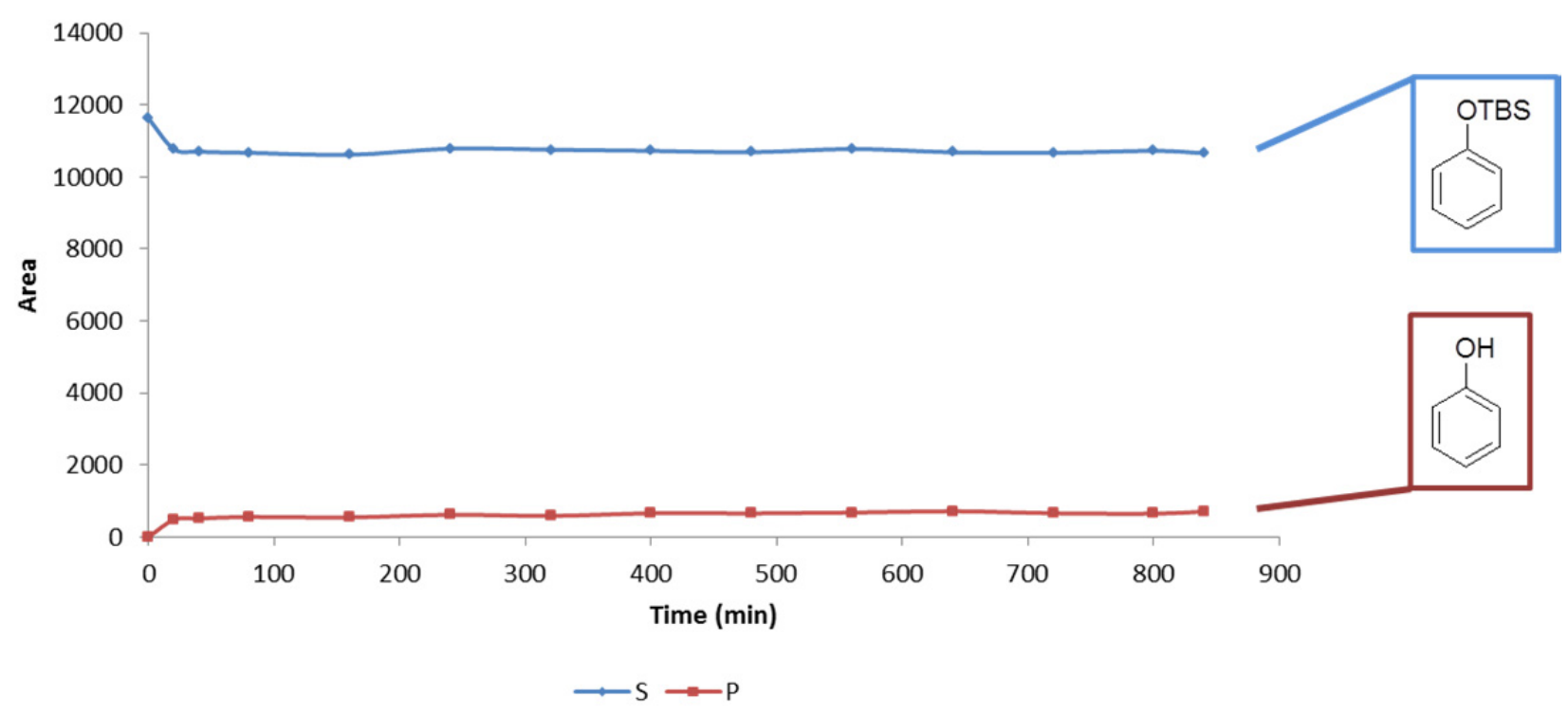

Figure 8. ${ }^{1} \mathrm{H}-\mathrm{NMR}$ kinetic study (Figure 7) of Compound 3. $(500 \mu \mathrm{M})$ reaction with TBAF $(25 \mu \mathrm{M})$. The normalized area of characteristic compound's peaks is plotted $v s$ reaction time.

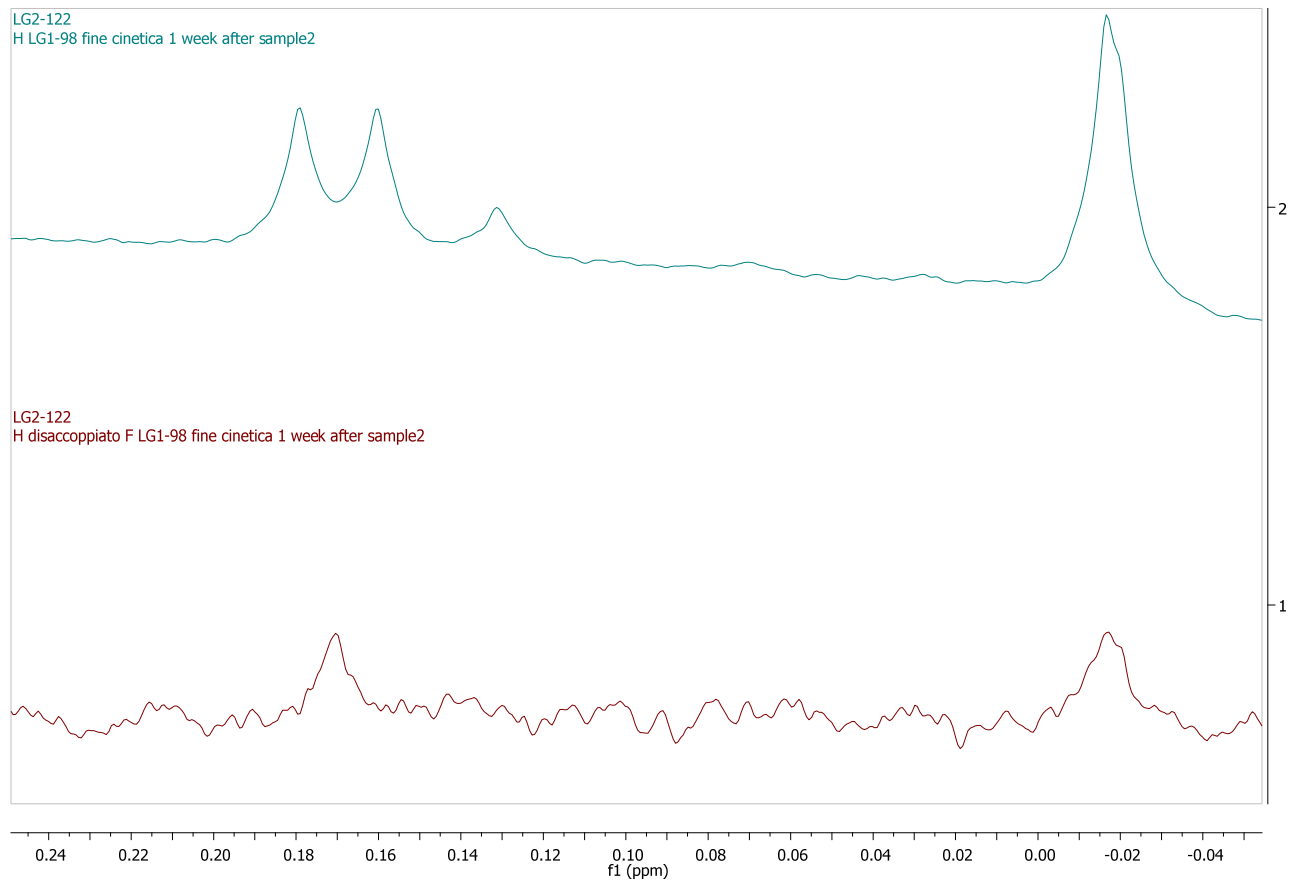

Figure 9. ${ }^{1} \mathrm{H}-\mathrm{NMR}$ spectra (up) vs. ${ }^{1} \mathrm{H}-\mathrm{NMR}$ decoupled ${ }^{19} \mathrm{~F}$ spectra (bottom) of probe $1500 \mu \mathrm{M}$, TBAF 25 $\mu \mathrm{M}$, in order to prove that peak at $0.17 \mathrm{ppm}$ is signal of $\mathrm{CH}_{3}$ in TBSF. In fact when ${ }^{1} \mathrm{H}$-NMR is ${ }^{19} \mathrm{~F}$ decoupled, the doublet with ${ }^{3} J_{H, F}=7.6 \mathrm{~Hz}$ becomes a singlet. 


\section{Additional UV-vis experiments.}

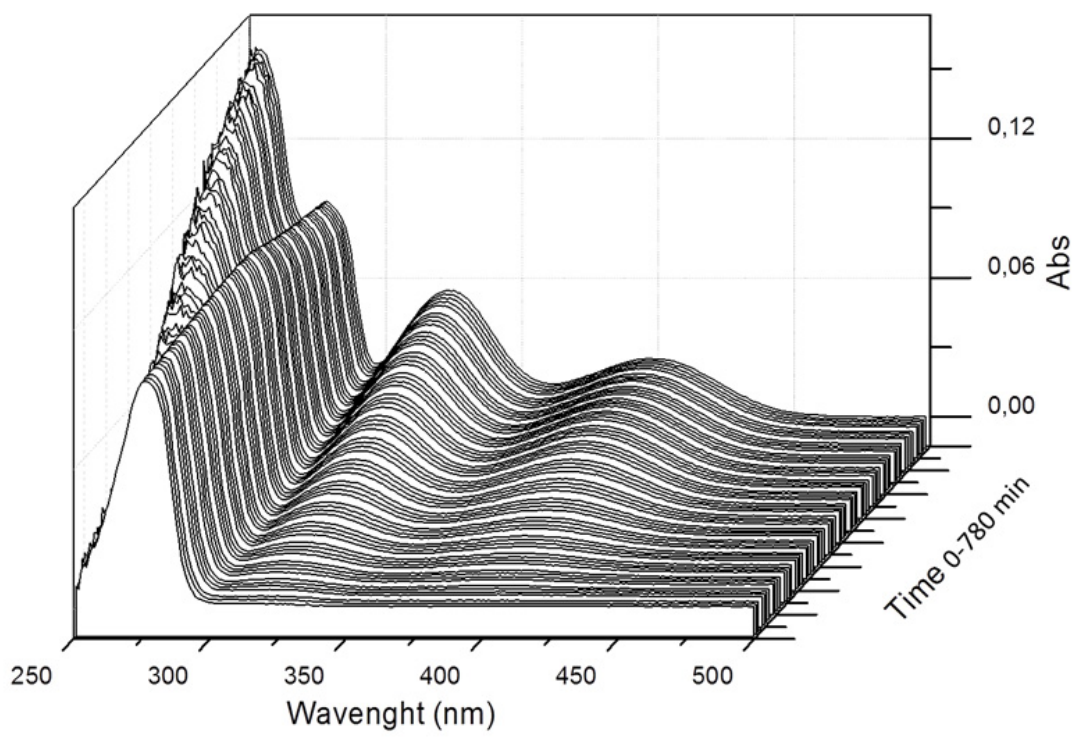

Figure 10. UV-vis spectra evolution of the disassembly reaction of probe $1(500 \mu \mathrm{M})$ in the presence of TBAF $25 \mu \mathrm{M}$; 1 cycle $/ 10$ min.

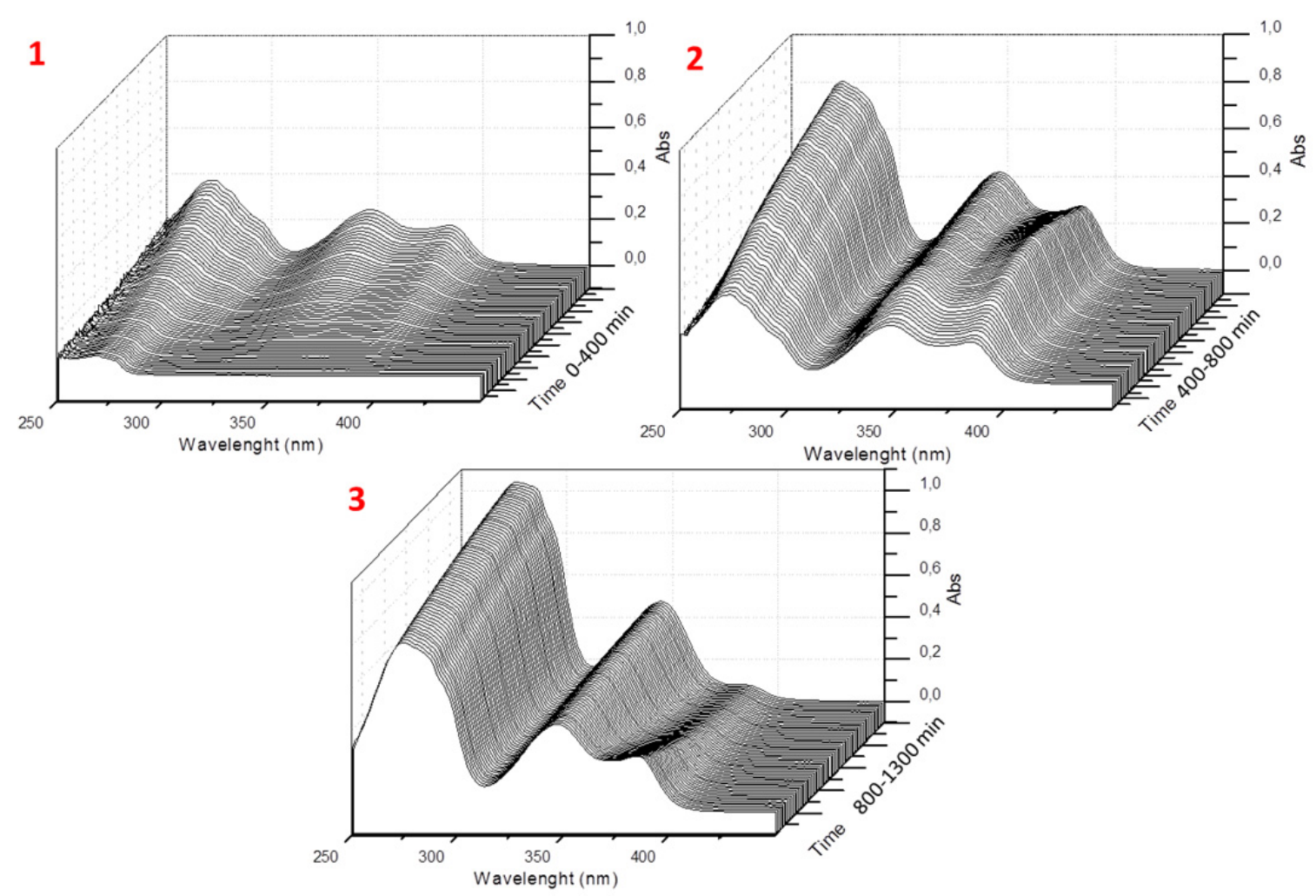

Figure 11. UV-vis spectra evolution of the disassembly reaction of probe $2(500 \mu \mathrm{M}))$ in the presence of TBAF $25 \mu \mathrm{M} ; 1$ cycle /min 


\section{UV Kinetic $400 \mathrm{~nm}: \boldsymbol{F}^{-} 25 \mu \mathrm{M}, 20,5 \div 50 \mathrm{mM}$}

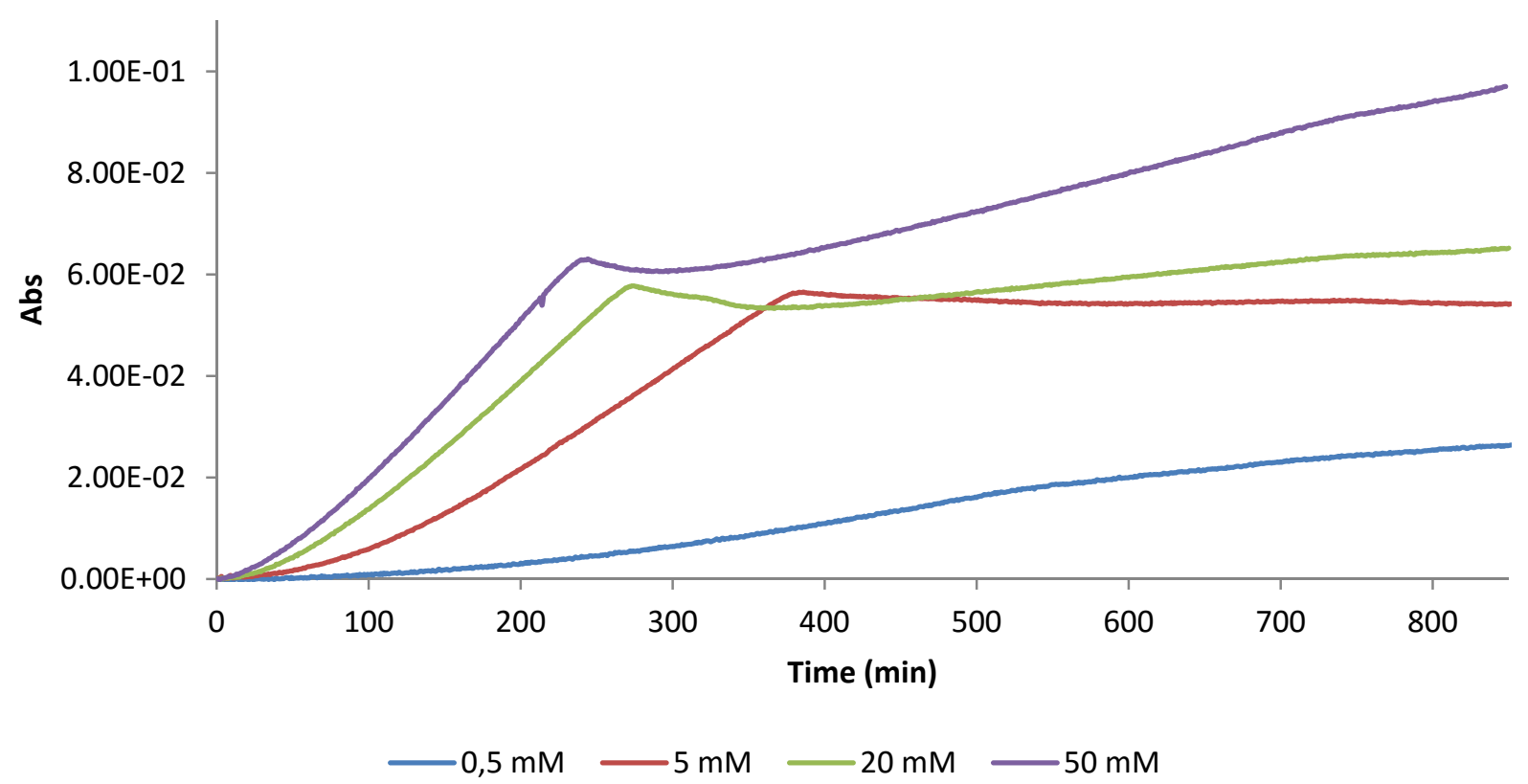

Figure 12. UV-vis kinetic experiment of probe concentration: probe $2(0.5 \div 50 \mathrm{mM})$, TBAF $25 \mu \mathrm{M}$, at 400 $\mathrm{nm}$. At constant initial $\mathrm{F}^{-}$concentration, the reaction's speed increases with the increasing of the probe concentration. This is expected for this self-immolative system, since the concentration of released $\mathrm{F}^{-}$is increasing with the increasing of the probe concentration.

UV Kinetic anion comparison (400 nm): $2500 \mu \mathrm{M}$,

$$
F^{-} 50 \mu \mathrm{M}, \boldsymbol{X}^{-} 100,500 \mu \mathrm{M}\left(\mathrm{X}^{-}=\mathrm{I}^{-}, \mathrm{Cl}, \mathrm{Br}, \mathrm{SO}_{4}{ }^{2-}\right)
$$

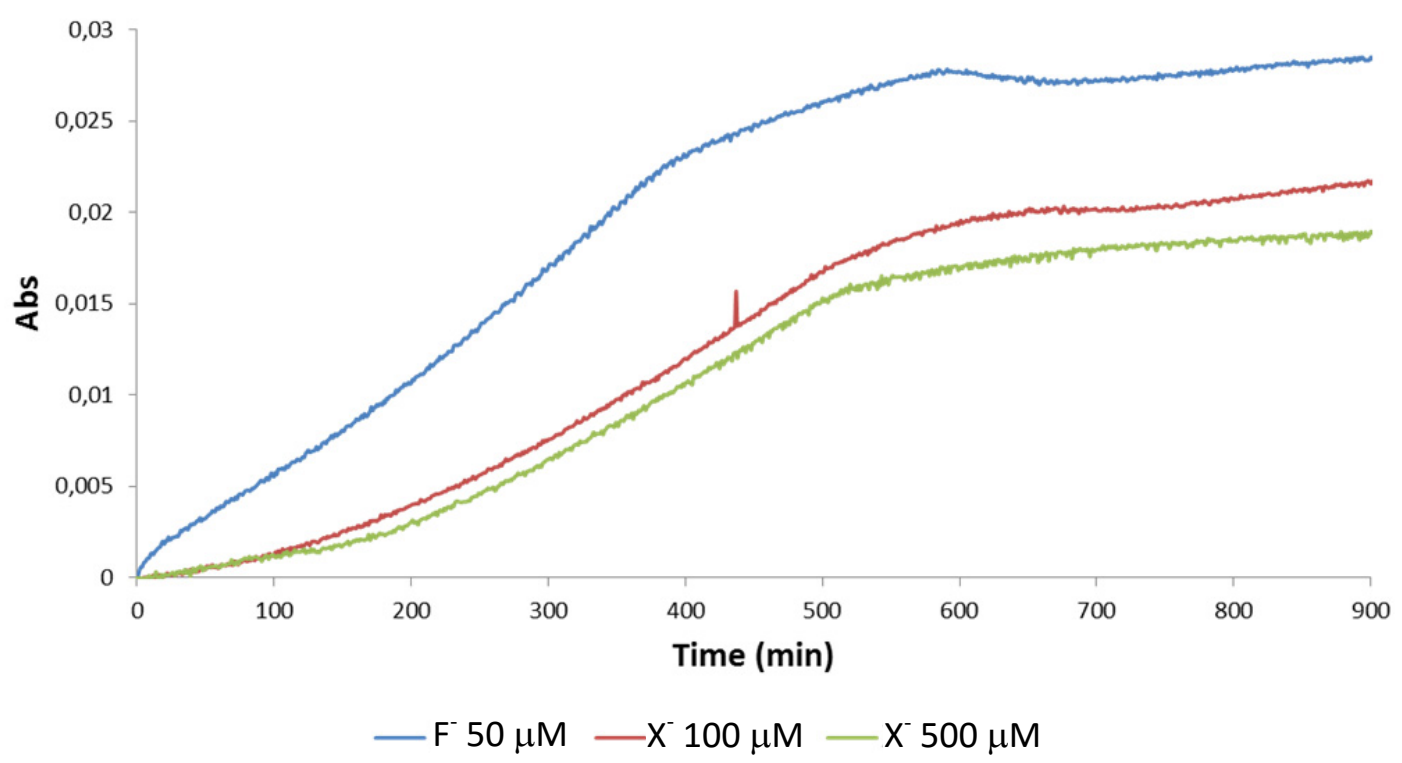

Figure 13. UV-vis kinetic experiment of anion selectivity: probe $1(500 \mu \mathrm{M})$, TBAF $50 \mu \mathrm{M} ; \mathrm{NaCl}, \mathrm{NaBr}$, $\mathrm{NaI}, \mathrm{Na}_{2} \mathrm{SO}_{4} 100 \mu \mathrm{M}$ and $500 \mu \mathrm{M}$ each, at $400 \mathrm{~nm}$. 


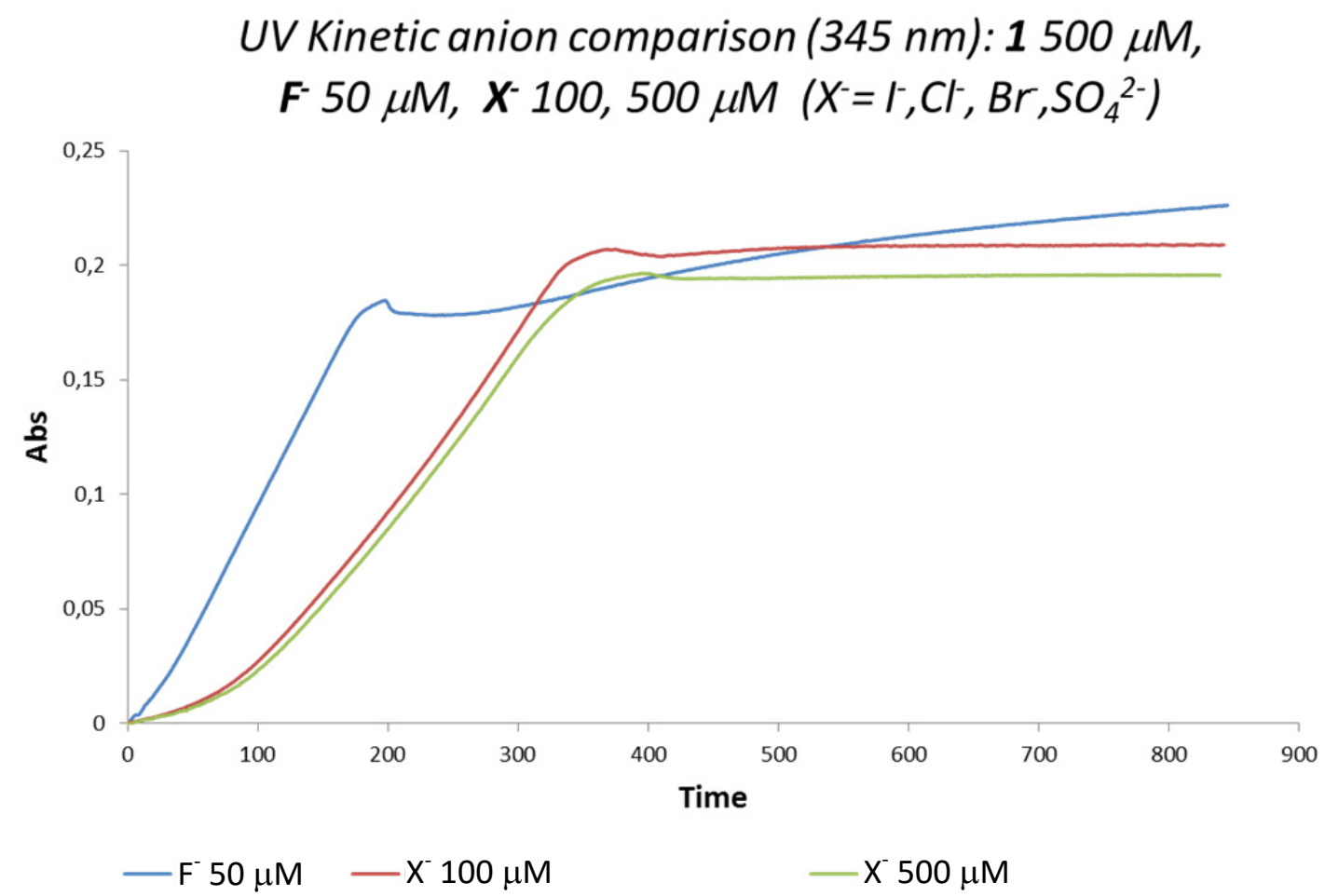

Figure 14. UV kinetic experiment of anion selectivity: probe $2(500 \mu \mathrm{M})$, TBAF $50 \mu \mathrm{M} ; \mathrm{NaCl}, \mathrm{NaBr}, \mathrm{NaI}$, $\mathrm{Na}_{2} \mathrm{SO}_{4} 100 \mu \mathrm{M}$ and $500 \mu \mathrm{M}$ each, at $345 \mathrm{~nm}$ :

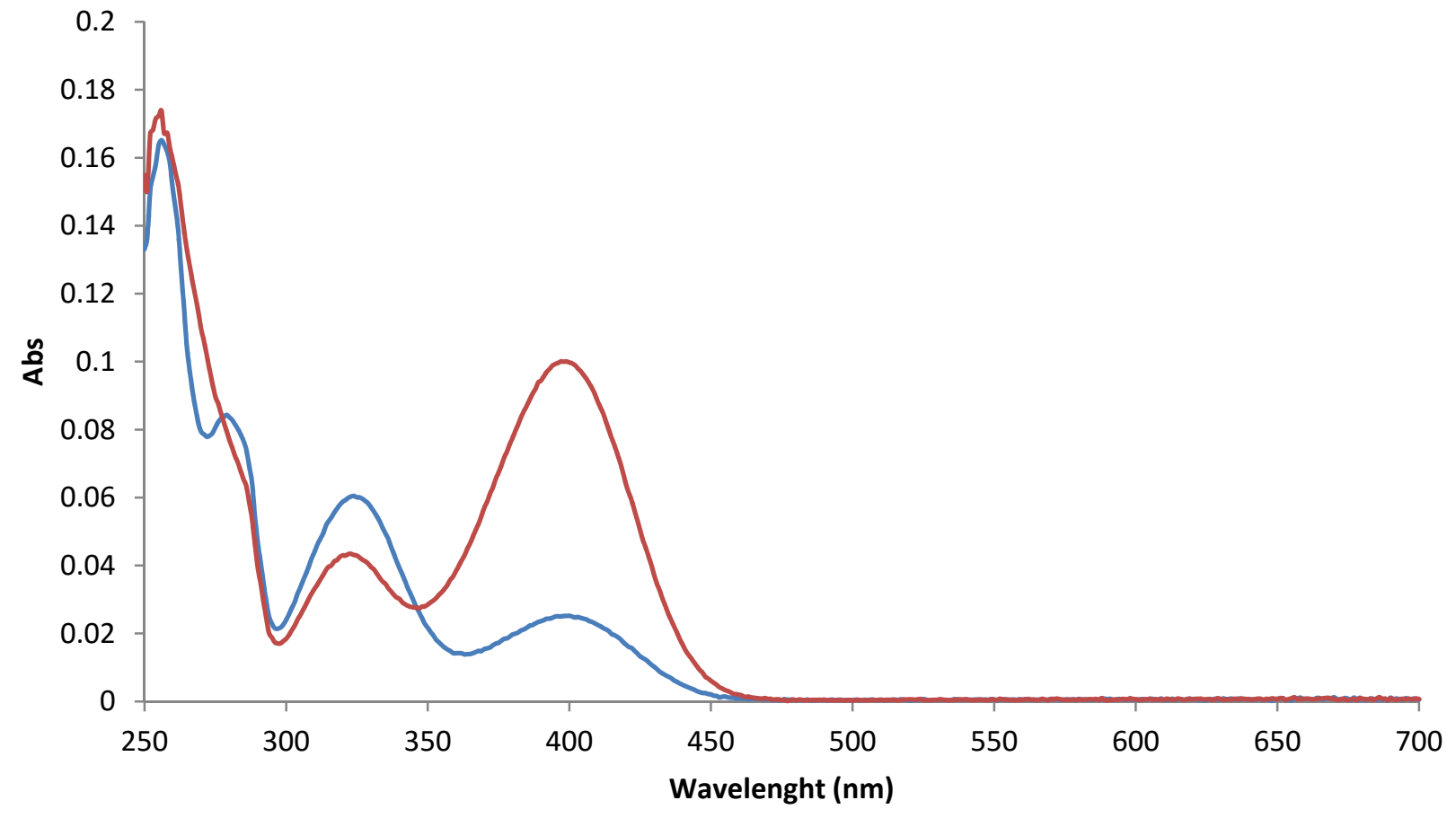

Salicylaldheyde before $\mathrm{Cs}_{2} \mathrm{CO}_{3} \longrightarrow$ Salicylaldheyde after $\mathrm{Cs}_{2} \mathrm{CO}_{3}$

Figure 15. Uv-vis spectra of $\mathrm{Cs}^{+}$effect on salicylaldehyde $(500 \mu \mathrm{M})$, before (blue) and after (red) the addition of $\mathrm{Cs}_{2} \mathrm{CO}_{3}(1 \mu \mathrm{L}$, final concentration $500 \mu \mathrm{M})$. 
UV kinetic $400 \mathrm{~nm}$ : Probe $1500 \mu \mathrm{M}, \mathrm{TBAF}$ 0-250 $\mu \mathrm{M} . \mathrm{Cs}_{2} \mathrm{CO}_{3}$

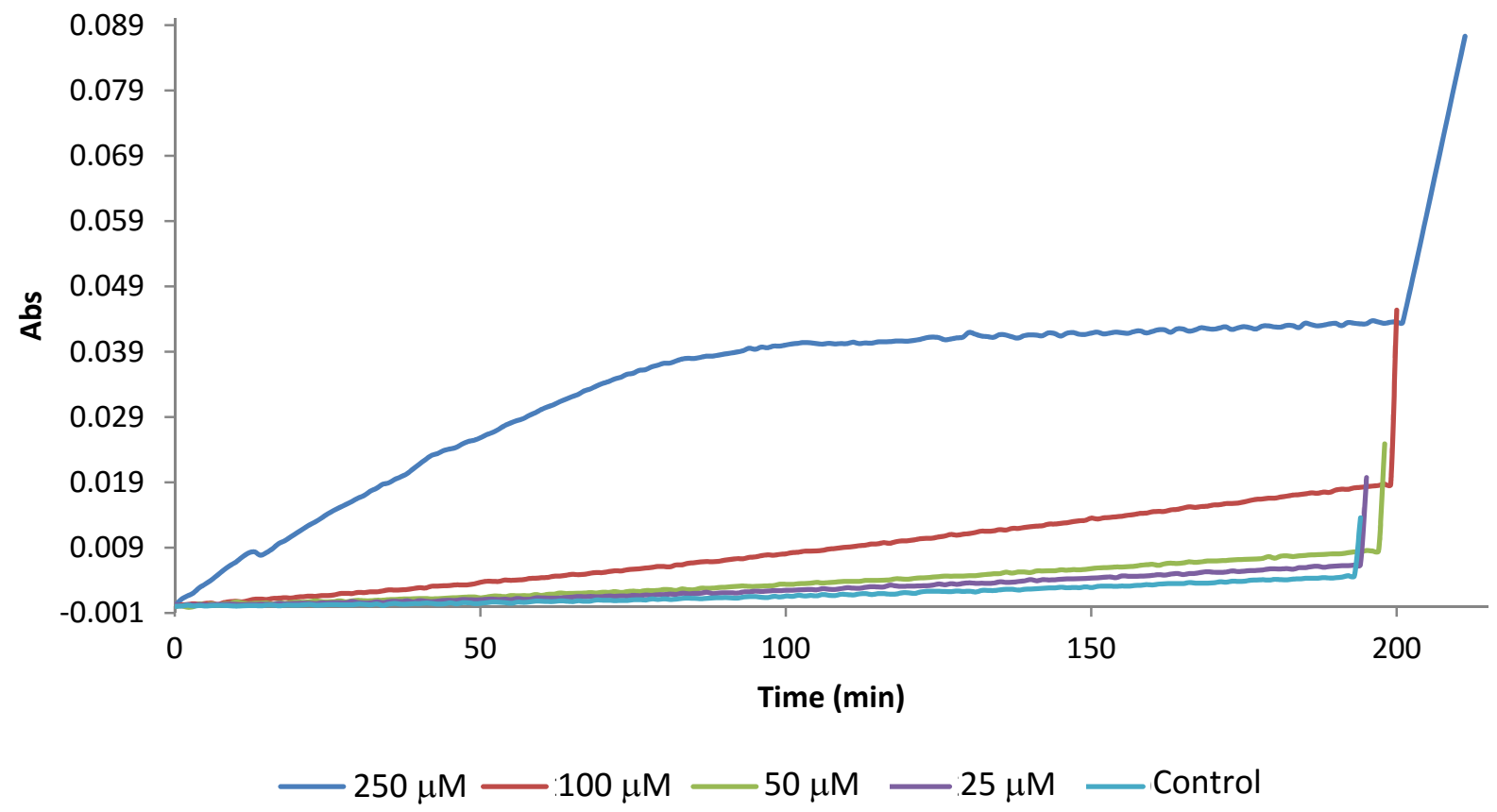

Figure 16. UV-vis kinetic experiment of $\mathrm{Cs}^{+}$effect on improving colorimetric detection $(400 \mathrm{~nm})$ : probe 1 $(500 \mu \mathrm{M})$, TBAF $0-250 \mu \mathrm{M} ; \mathrm{Cs}_{2} \mathrm{CO}_{3},(1 \mu \mathrm{L}$, final concentration $500 \mu \mathrm{M})$ added after $200 \mathrm{~min}$.

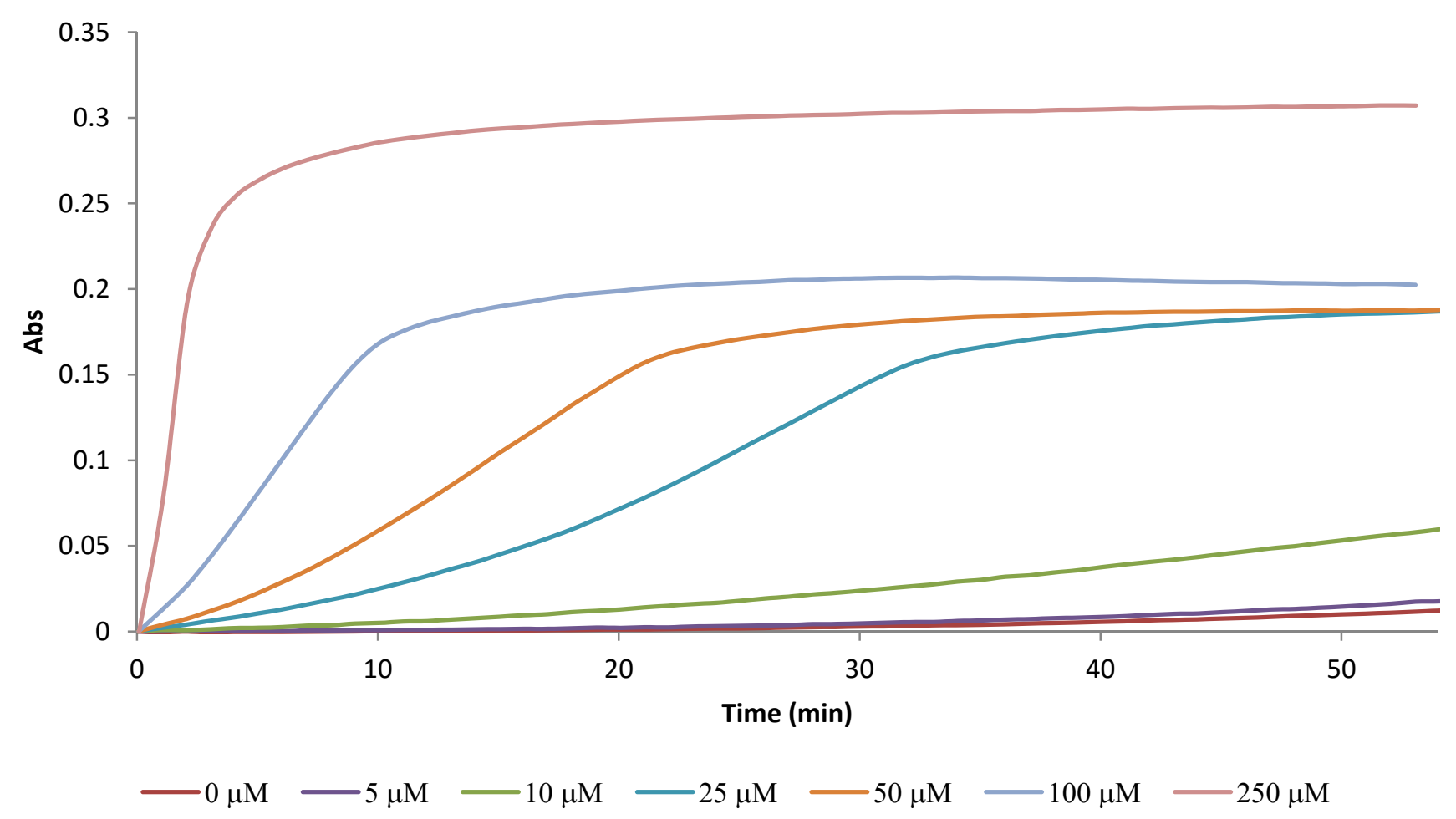

Figure 17. UV-vis kinetic experiment at $50^{\circ} \mathrm{C}$ : probe $2(500 \mu \mathrm{M})$, TBAF $25-250 \mu \mathrm{M}$; DMSO:ACN: $\mathrm{H}_{2} \mathrm{O}$ :triethylamine 47:47:5:0.5, at $345 \mathrm{~nm}$. 


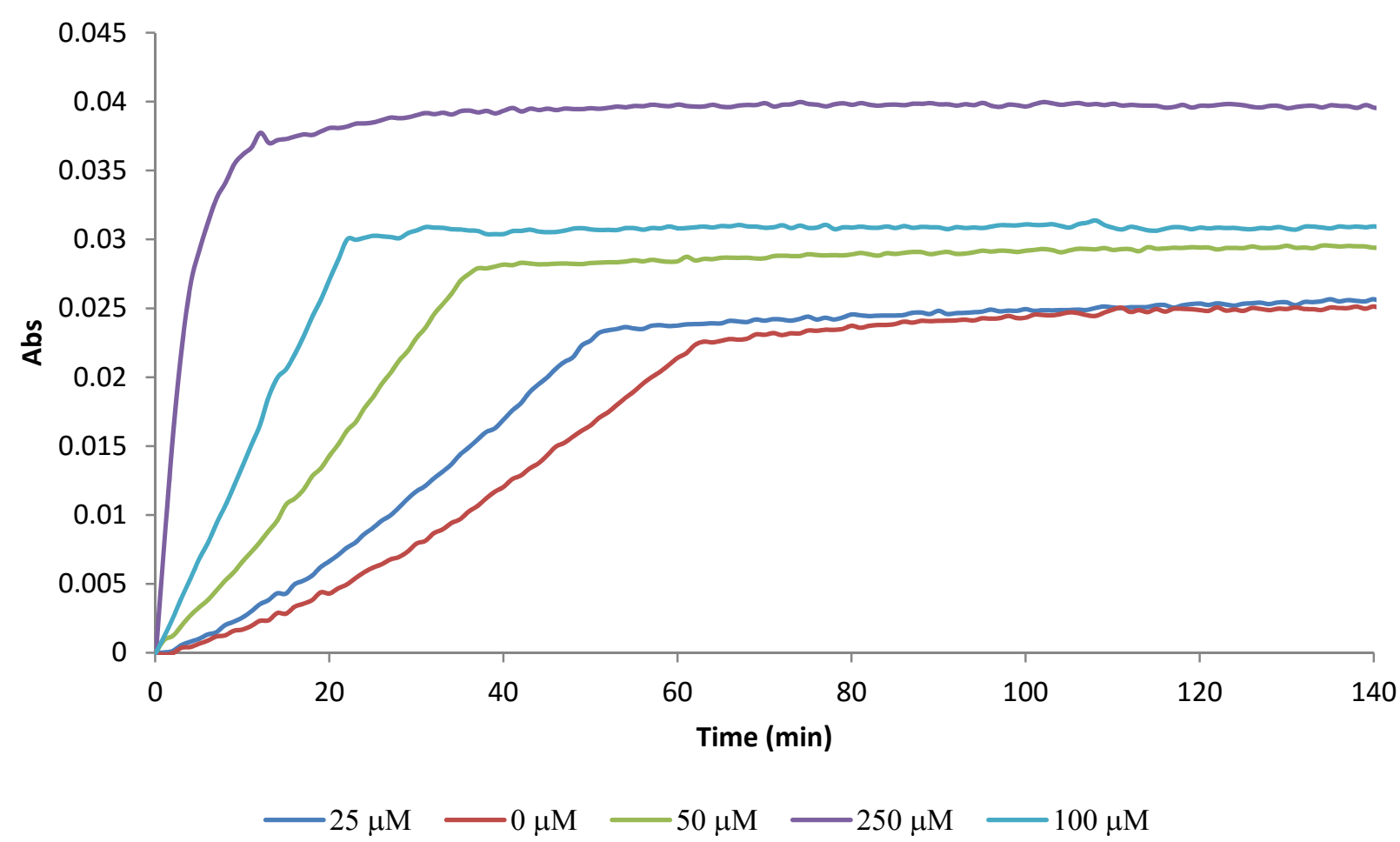

Figure 18. UV-vis kinetic experiment at $50^{\circ} \mathrm{C}$ : probe $1(500 \mu \mathrm{M})$, TBAF $25-250 \mu \mathrm{M}$; DMSO:ACN: $\mathrm{H}_{2} \mathrm{O}:$ triethylamine 47:47:5:0.5, at $400 \mathrm{~nm}$.

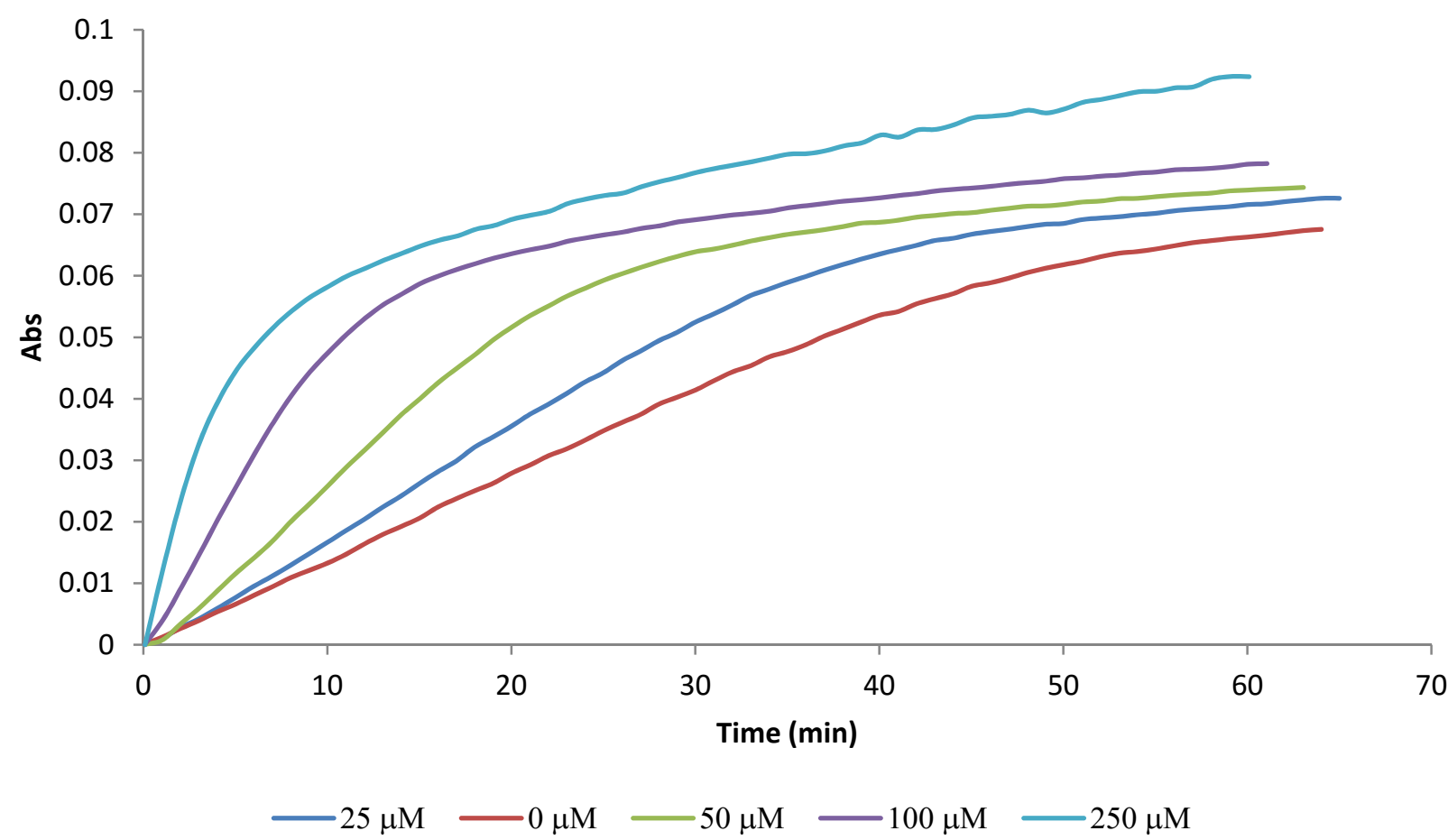

Figure 19. UV-vis kinetic experiment at optimized conditions: probe $1(500 \mu \mathrm{M})$, TBAF $25-250 \mu \mathrm{M}$; DMSO:ACN: $\mathrm{H}_{2} \mathrm{O} 37: 37: 25,50^{\circ} \mathrm{C}$ at $388 \mathrm{~nm}$. 


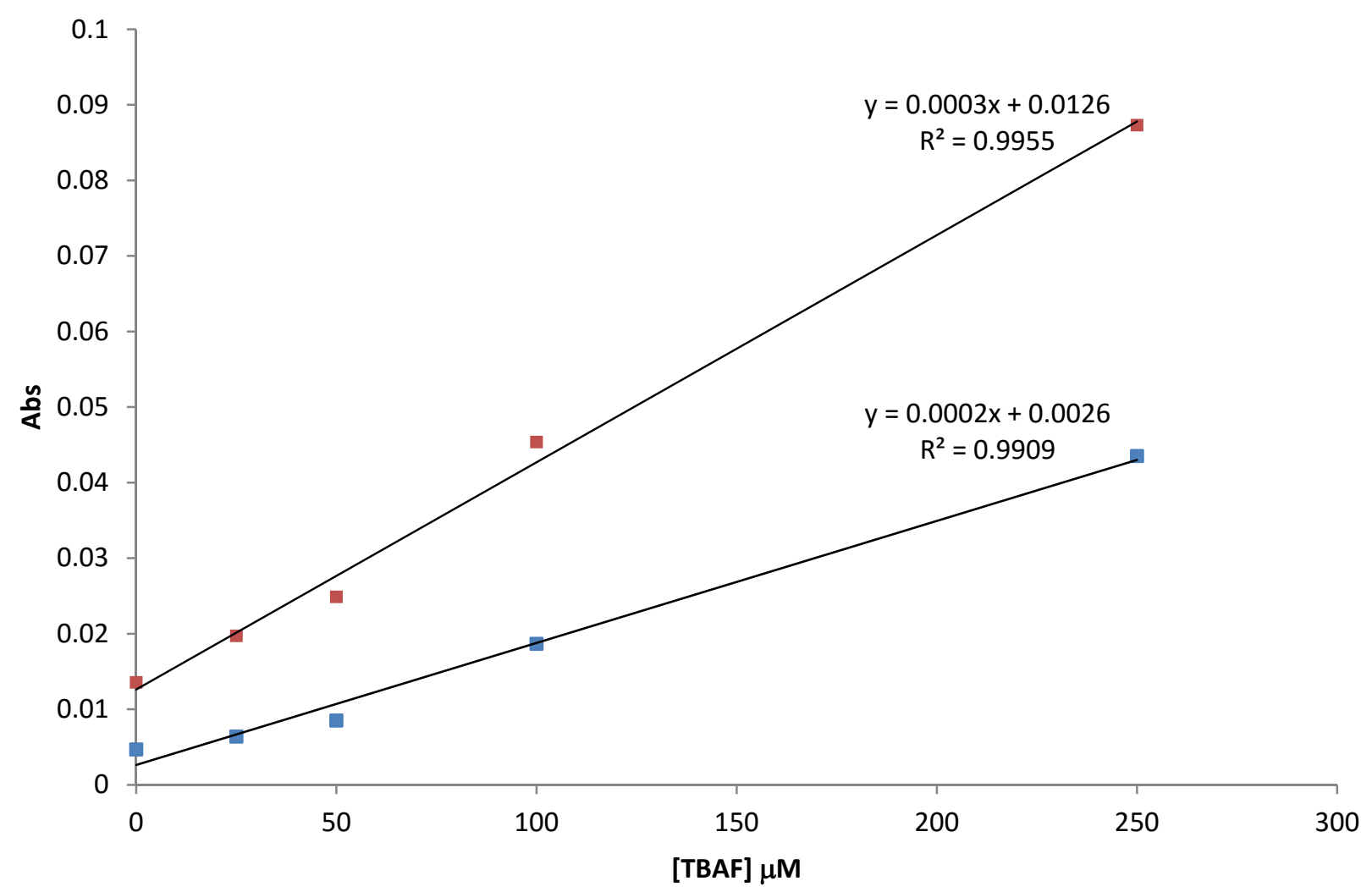

- Abs before $\mathrm{Cs}_{2} \mathrm{CO}_{3}$ - Abs after $\mathrm{Cs}_{2} \mathrm{CO}_{3}$

Figure 20. Uv-vis kinetic experiment of $\mathrm{Cs}^{+}$effect on improving colorimetric detection (400 nm): probe 1 $(500 \mu \mathrm{M})$, TBAF 0-250 $\mu \mathrm{M} ; \mathrm{Cs}_{2} \mathrm{CO}_{3}(1 \mu \mathrm{L}$, final concentration $500 \mu \mathrm{M})$ added after $200 \mathrm{~min}$. Relationship between absorbance and TBAF concentration before and after addition of $\mathrm{Cs}_{2} \mathrm{CO}_{3}$.

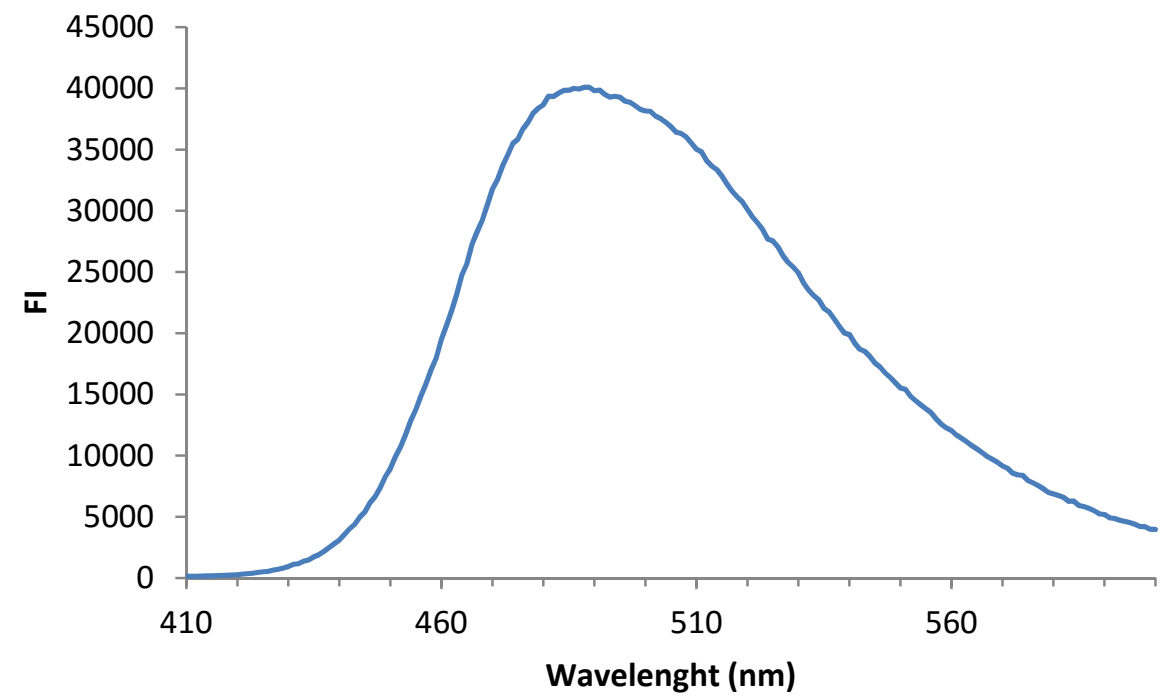

Figure 21. Fluorescence emission spectra of salicylaldehyde (500 $\mu \mathrm{M}$, DMSO: $\mathrm{ACN}: \mathrm{H}_{2} \mathrm{O}$ :triethylamine 47:47:5:0.5, Ex $400 \mathrm{~nm})$ 
3. ${ }^{1} \mathrm{H},{ }^{13} \mathrm{C},{ }^{19} \mathrm{~F},{ }^{29} \mathrm{SI}-\mathrm{NMR}$ and MS spectra of the synthesized compounds.
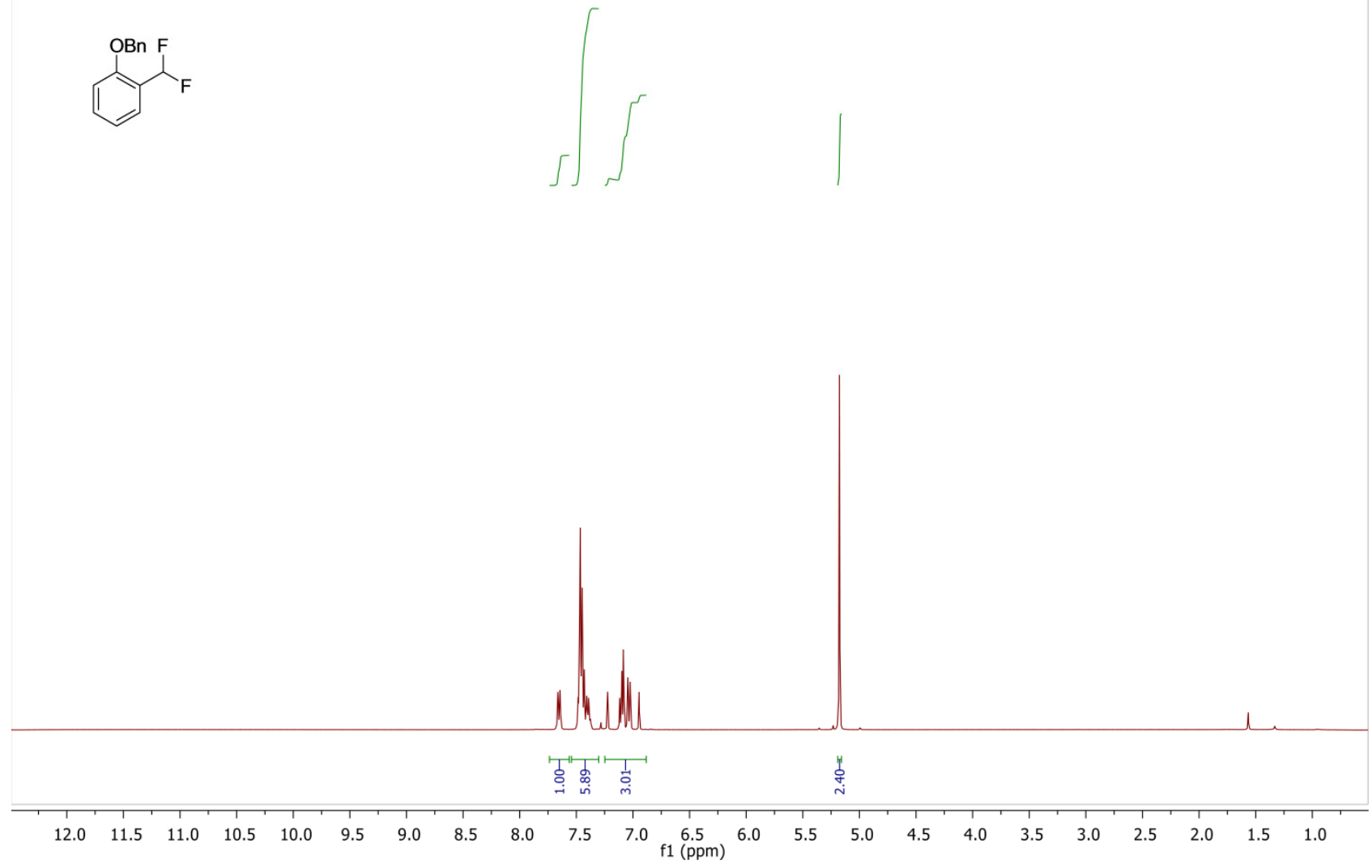

Figure 22. ${ }^{1} \mathrm{H}$ NMR spectra of compound 30 


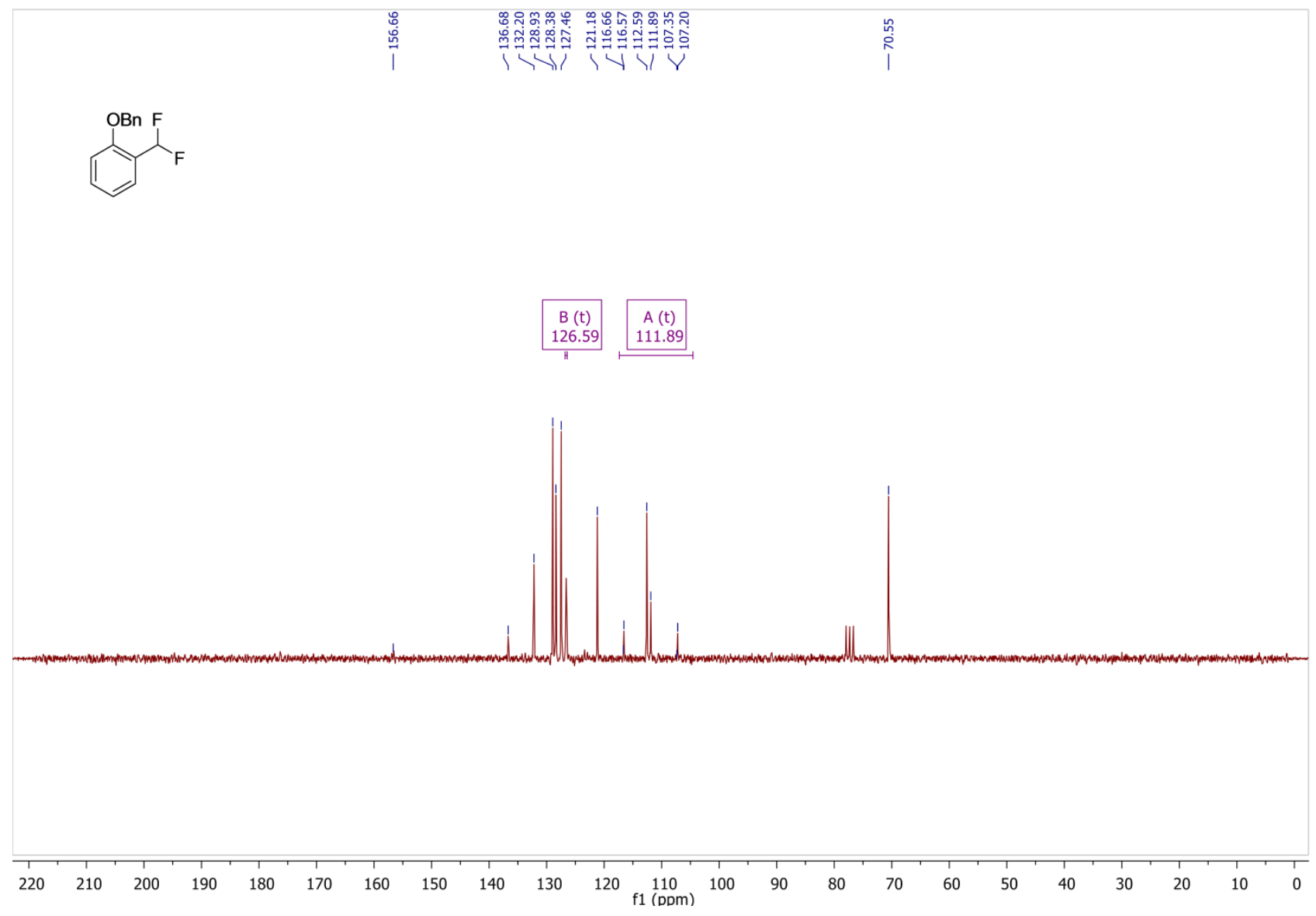

Figure 23. ${ }^{13} \mathrm{C}$ NMR spectra of compound 30 . 
<smiles>Oc1ccccc1C(F)F</smiles>

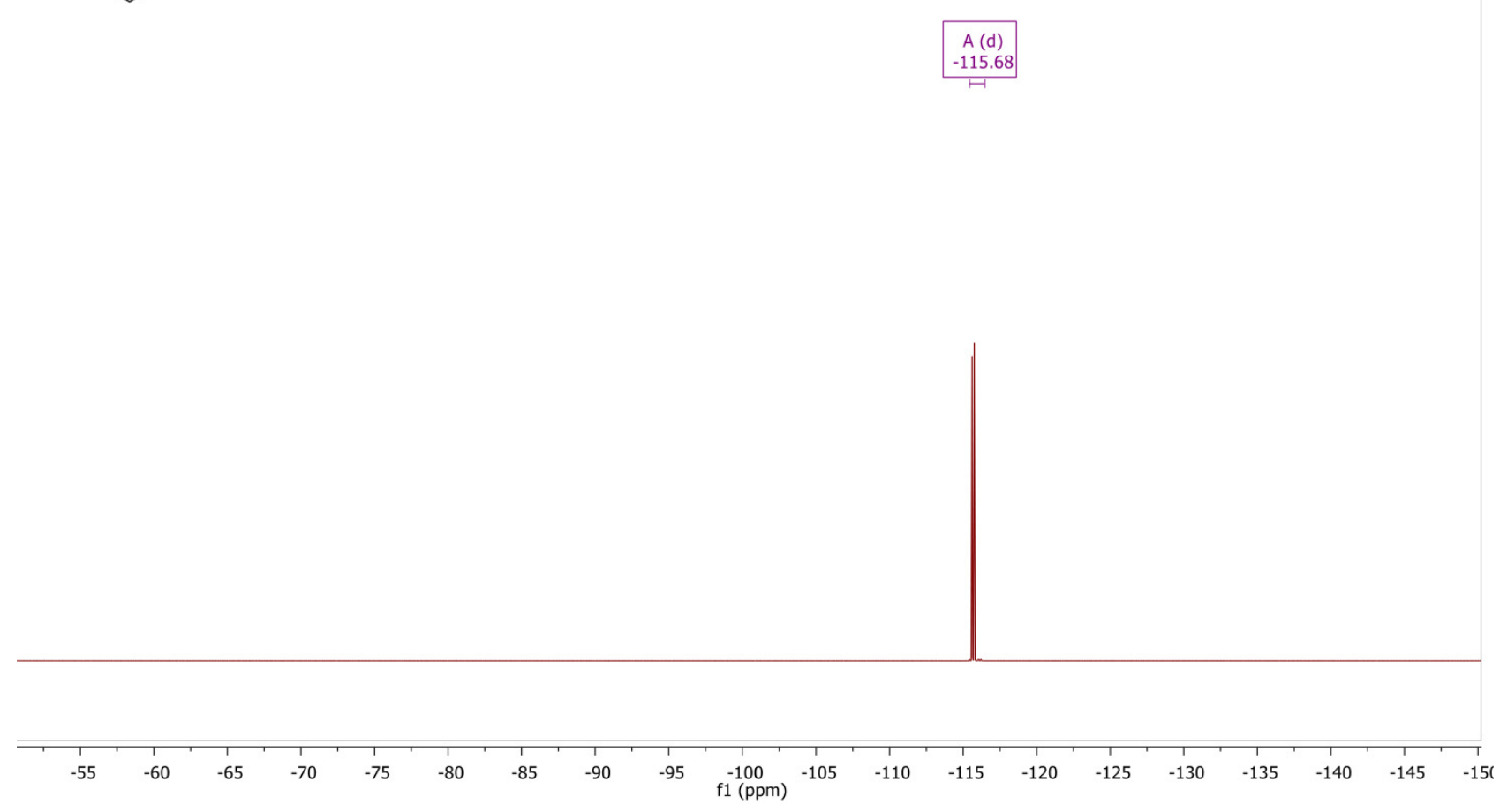

Figure 24. ${ }^{19} \mathrm{~F}$ NMR spectra of compound 30. 


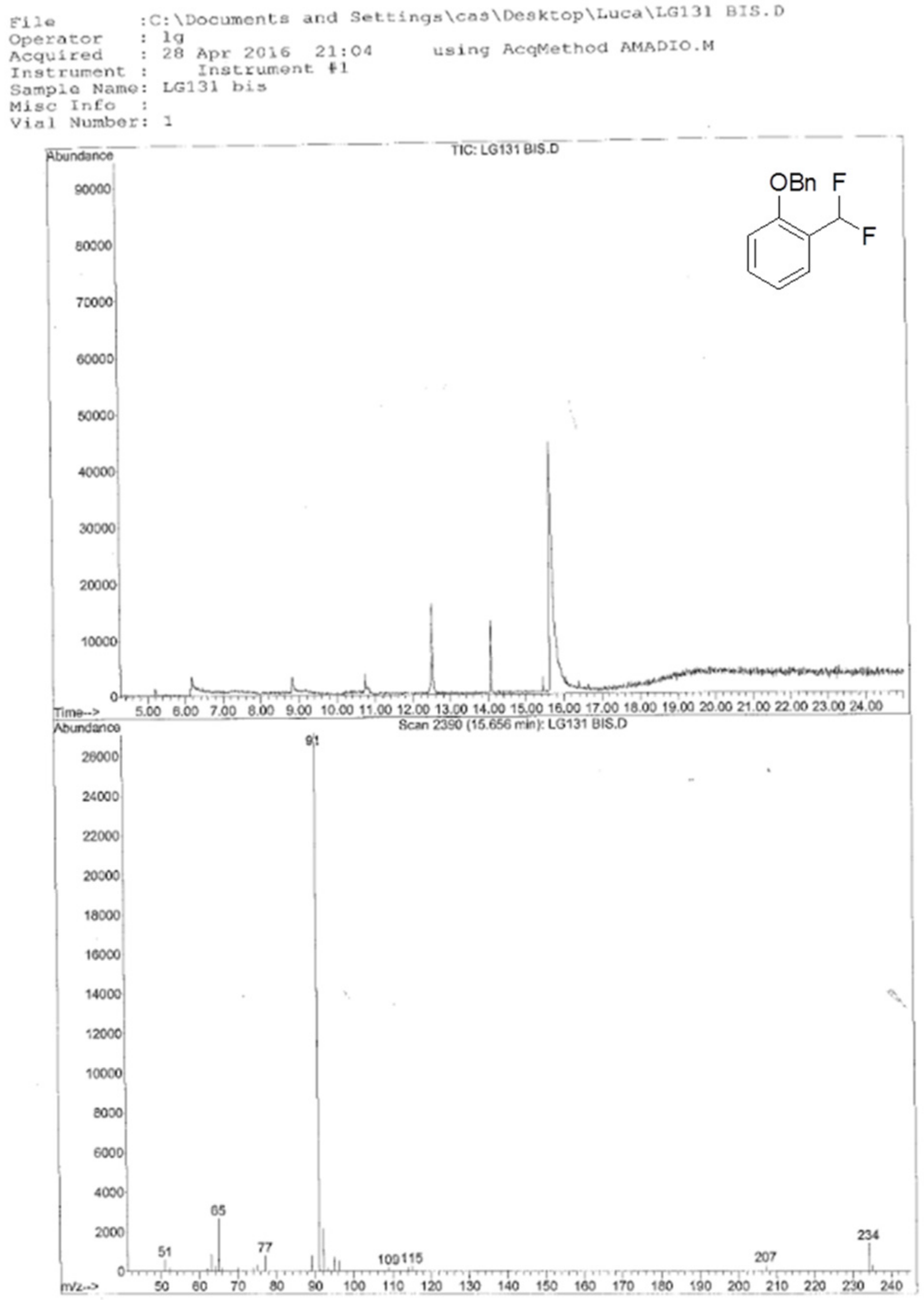

Figure 25. GCMS spectra of compound 30. 


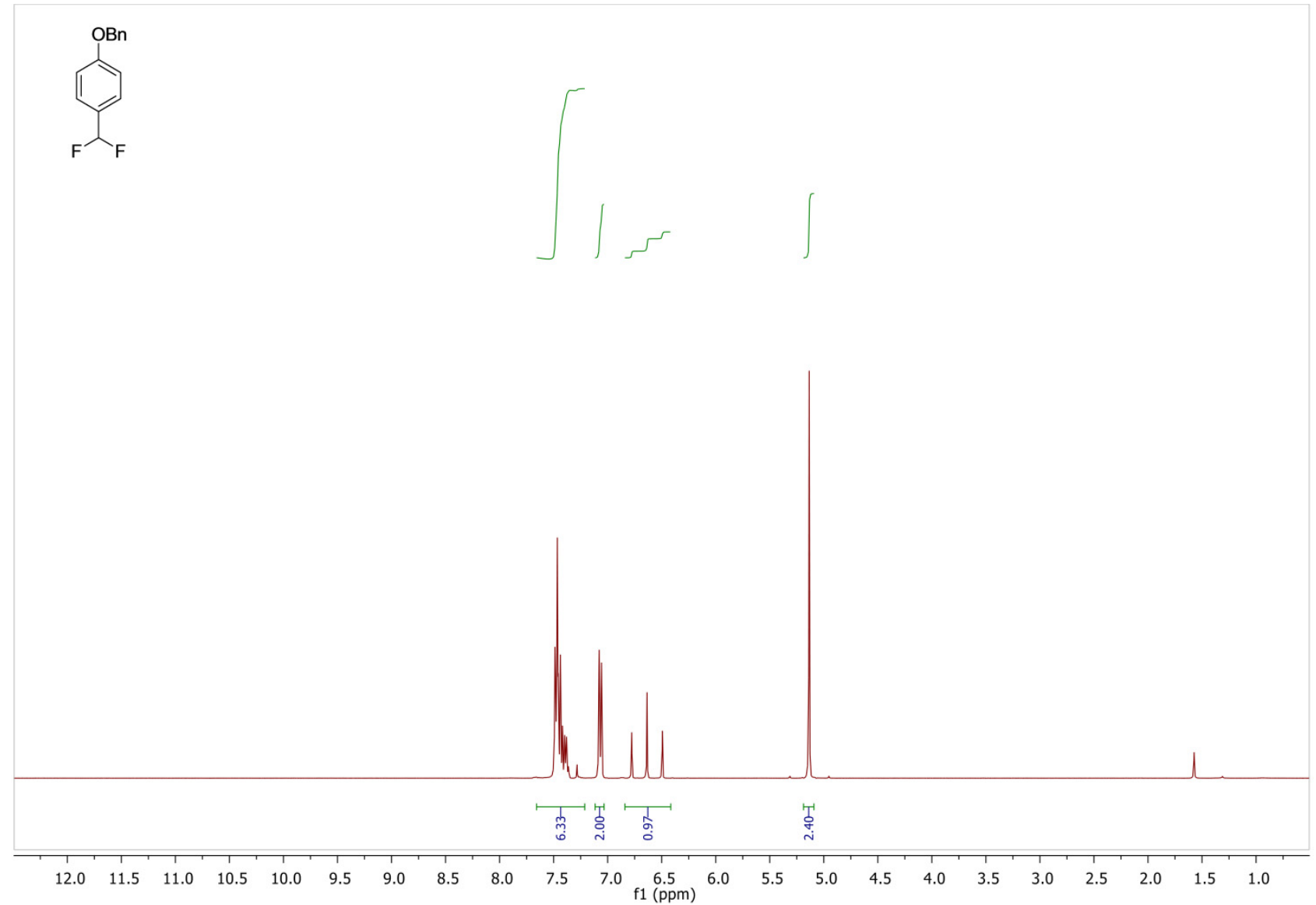

Figure 26. ${ }^{1} \mathrm{H}$ NMR spectra of compound $\mathbf{3 p}$ 


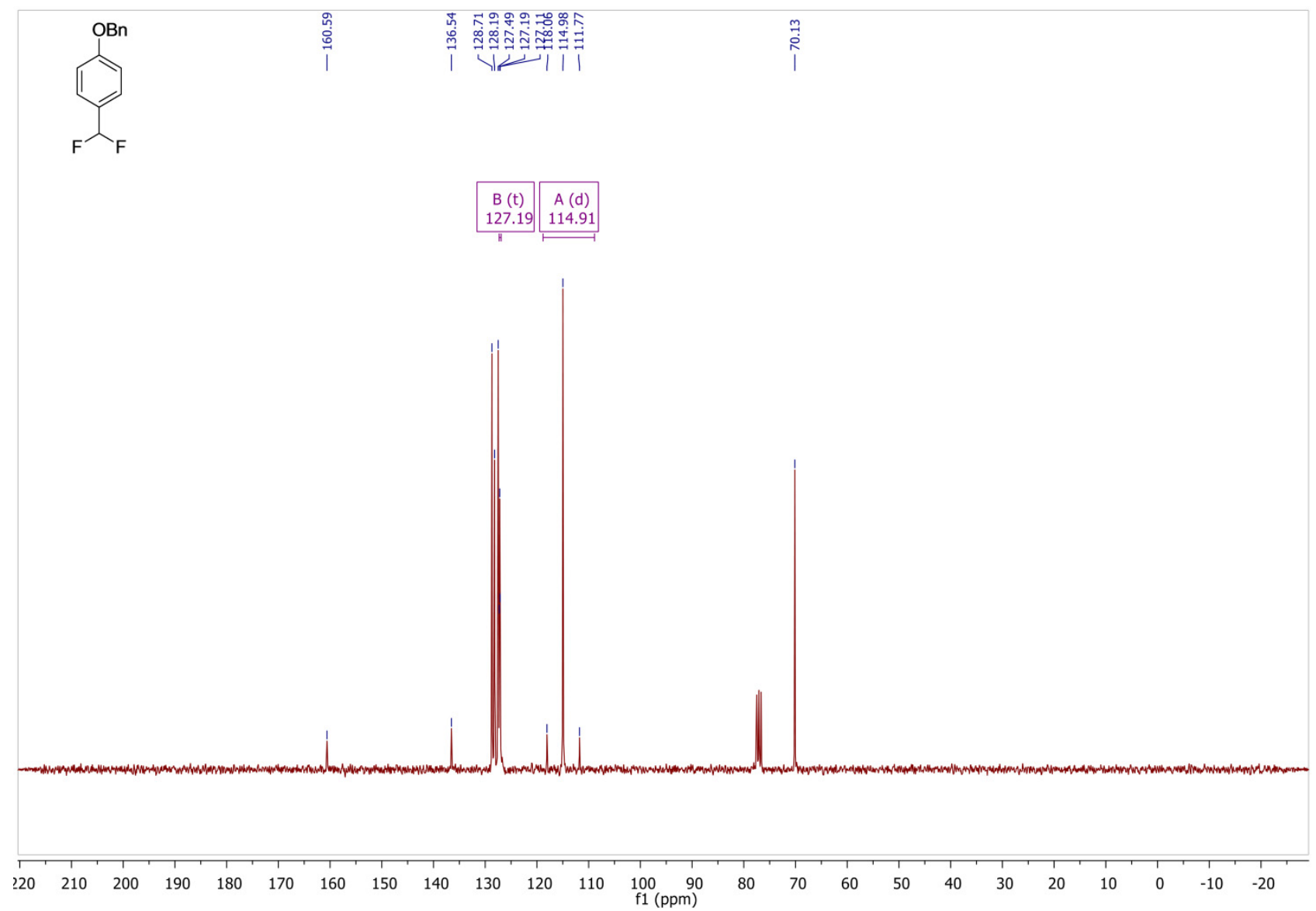

Figure 27. ${ }^{13} \mathrm{C}$ NMR spectra of compound $\mathbf{3 p}$. 


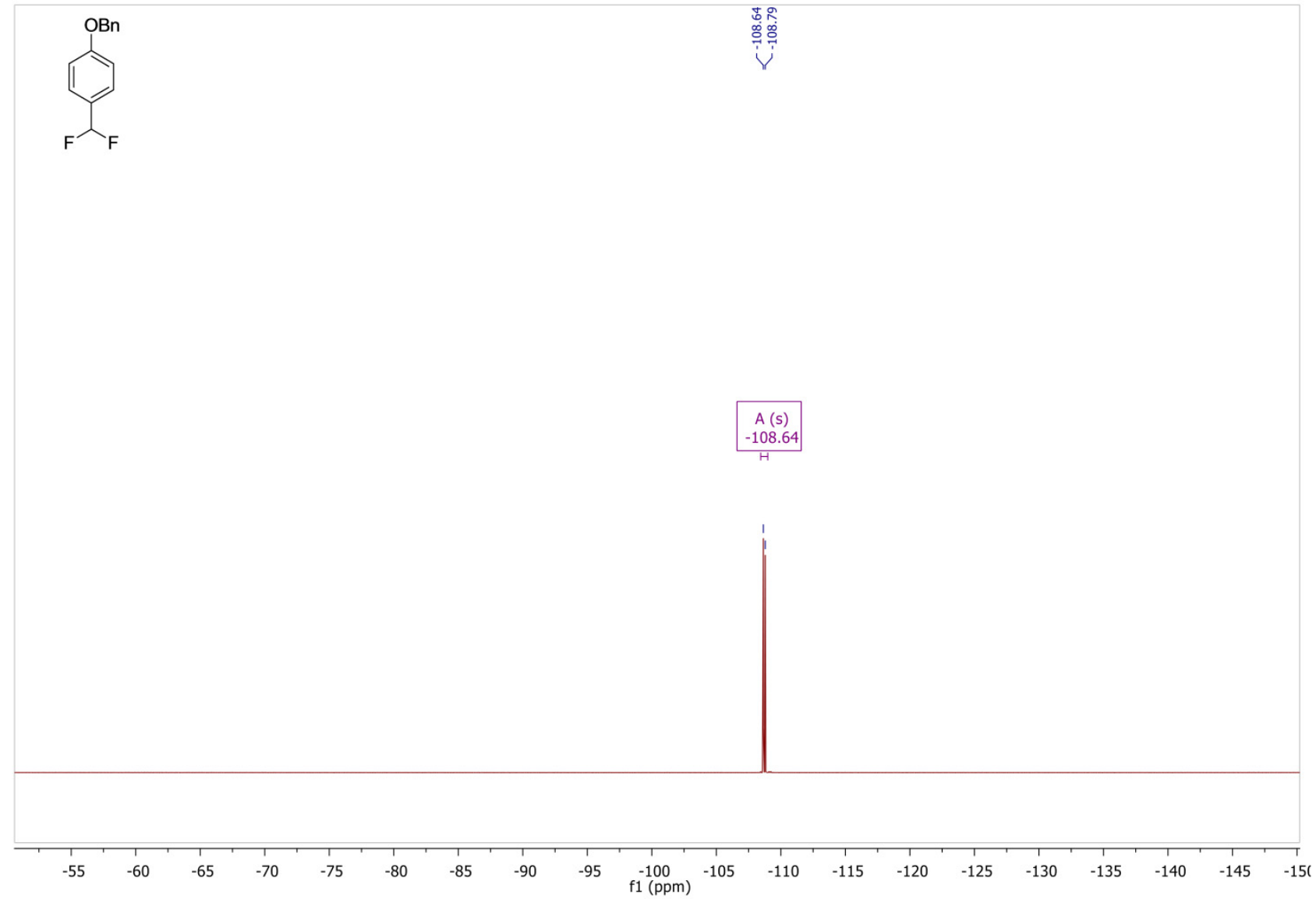

Figure 28. ${ }^{19} \mathrm{~F}$ NMR spectra of compound 3p. 


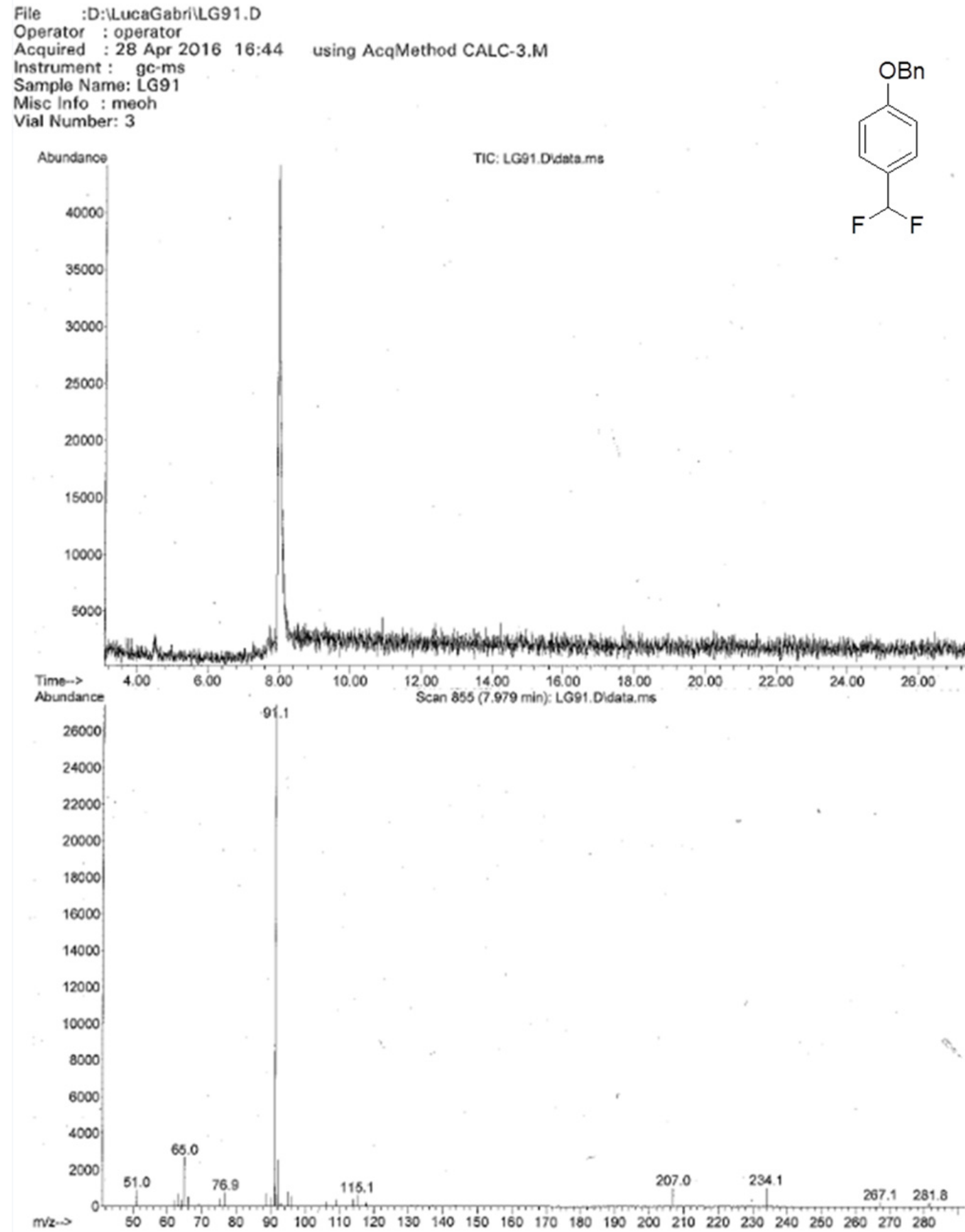

Figure 29. GCMS spectra of compound 3p. 


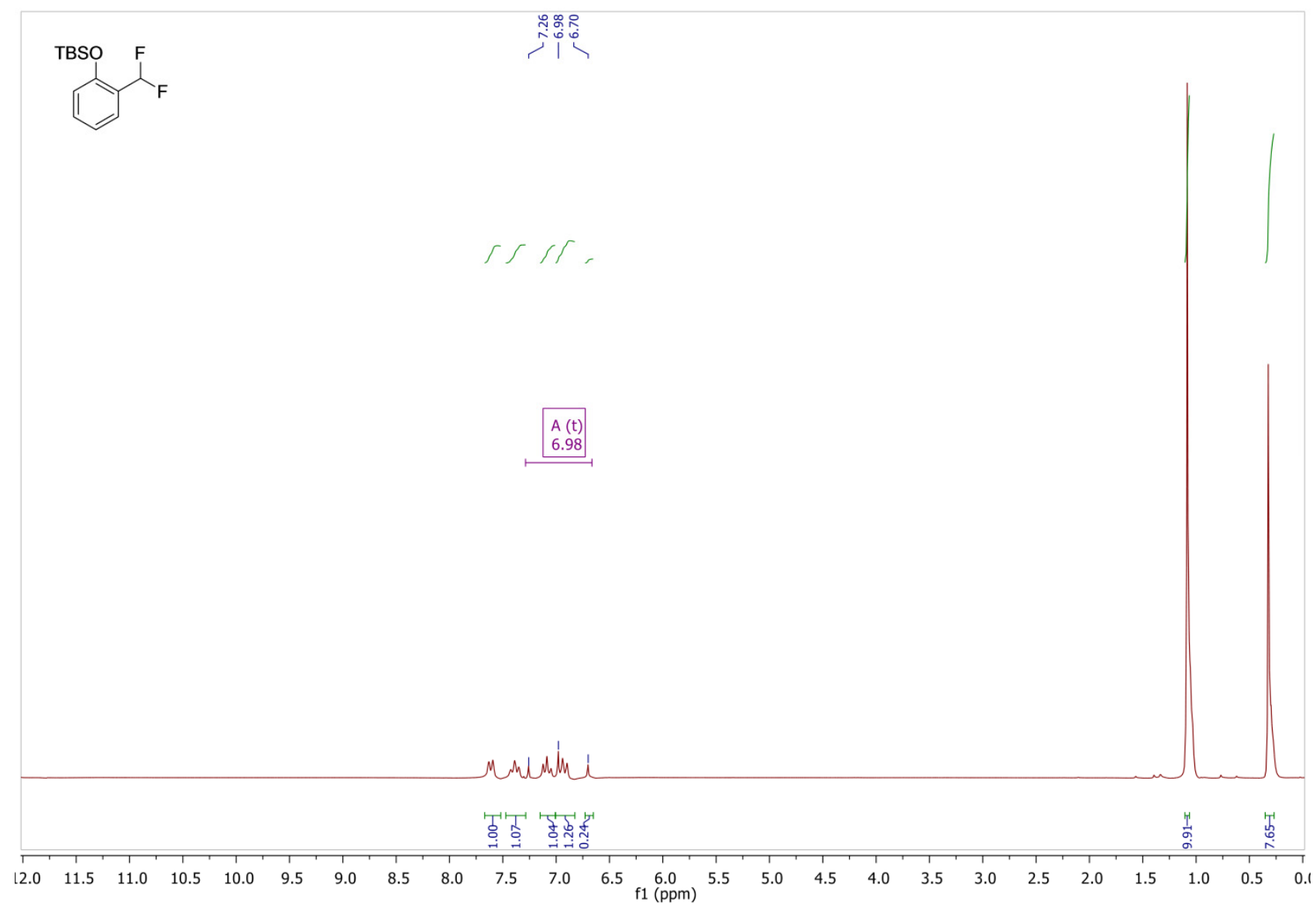

Figure 30. ${ }^{1} \mathrm{H}$ NMR spectra of compound 1 


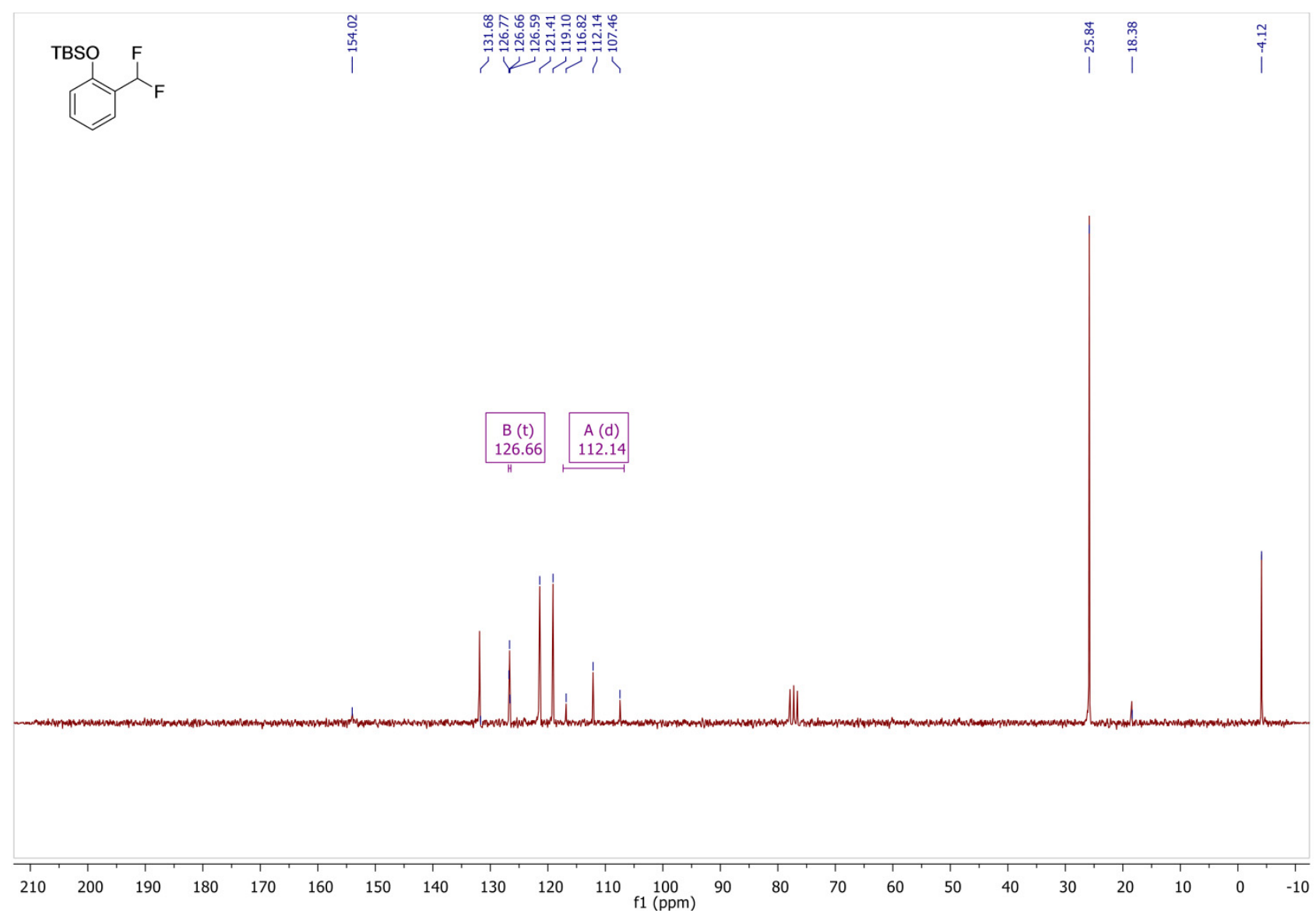

Figure 31. ${ }^{13} \mathrm{C}$ NMR spectra of compound $\mathbf{1}$. 


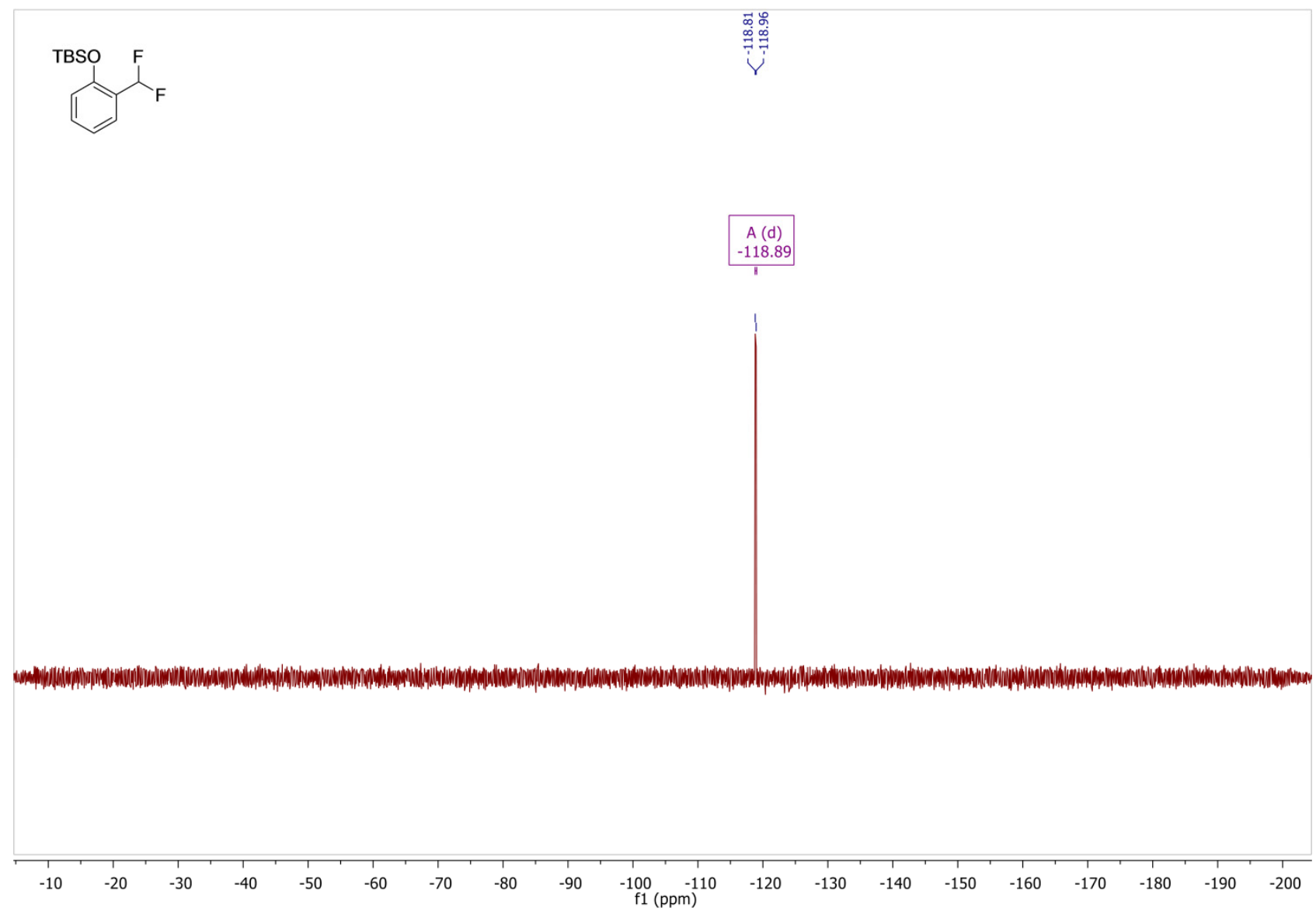

Figure 32. ${ }^{19} \mathrm{~F}$ NMR spectra of compound $\mathbf{1}$. 


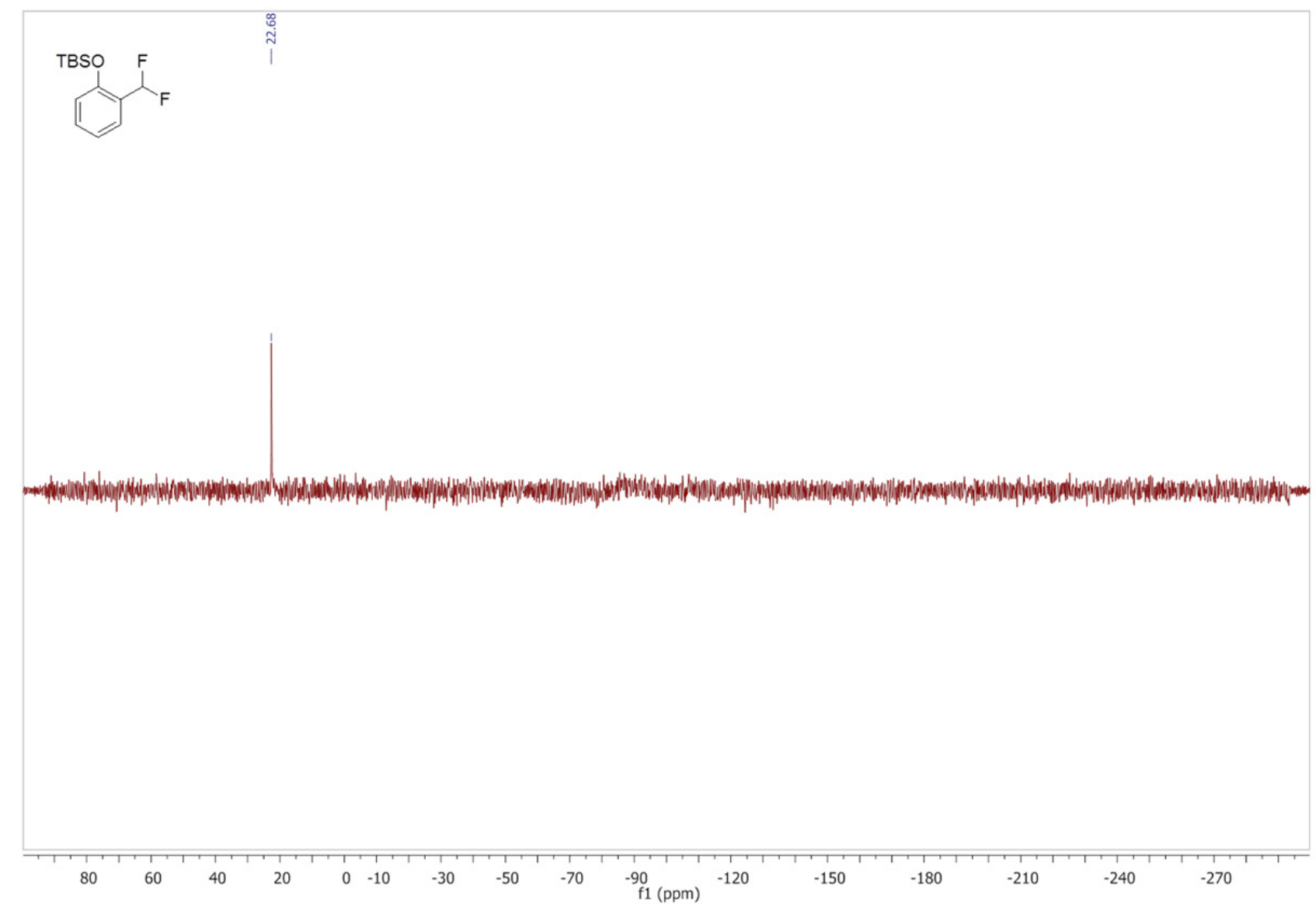

Figure 33. ${ }^{29} \mathrm{Si}$ NMR spectra of compound 1. 


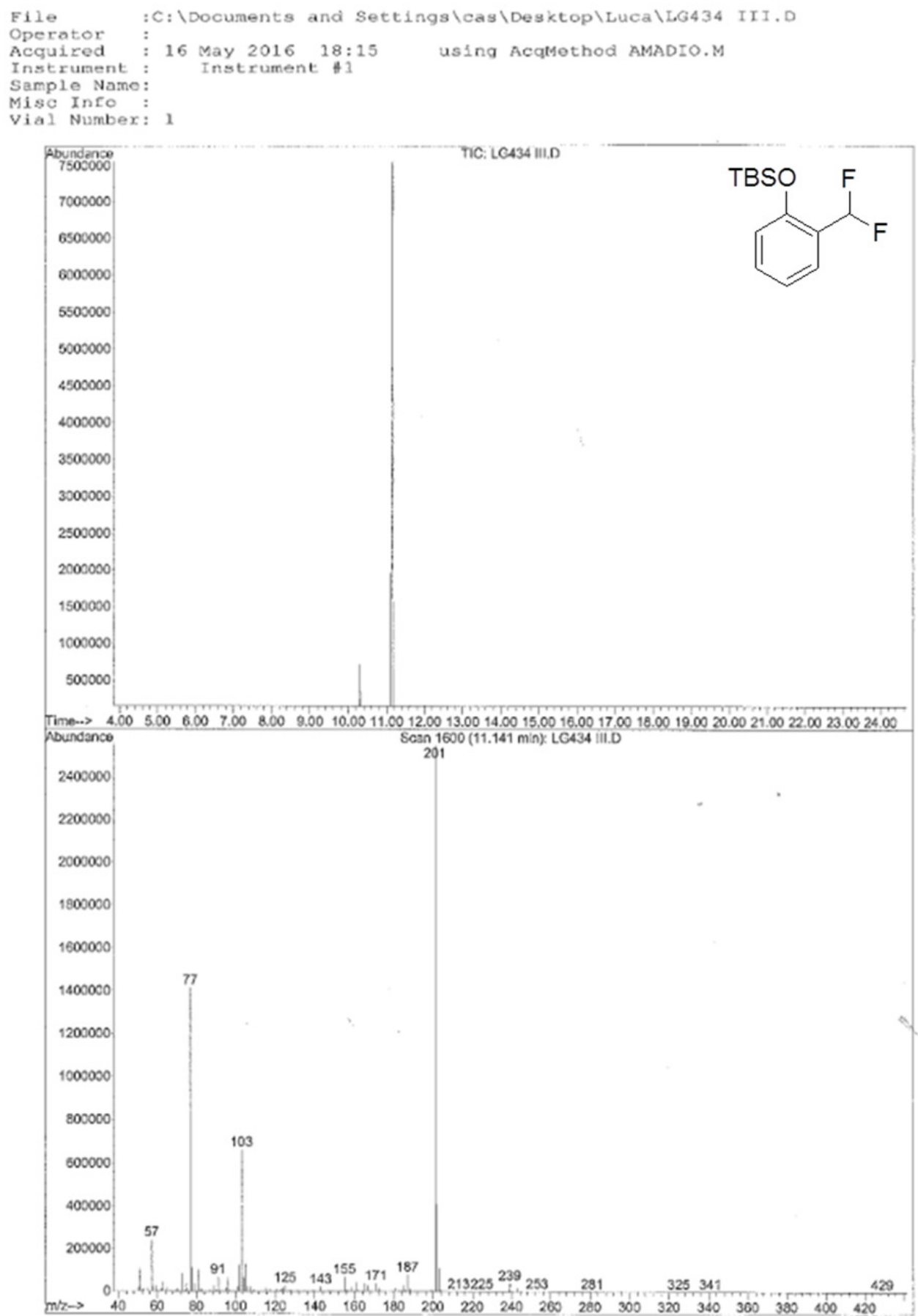

Figure 34. GCMS spectra of compound 1. 


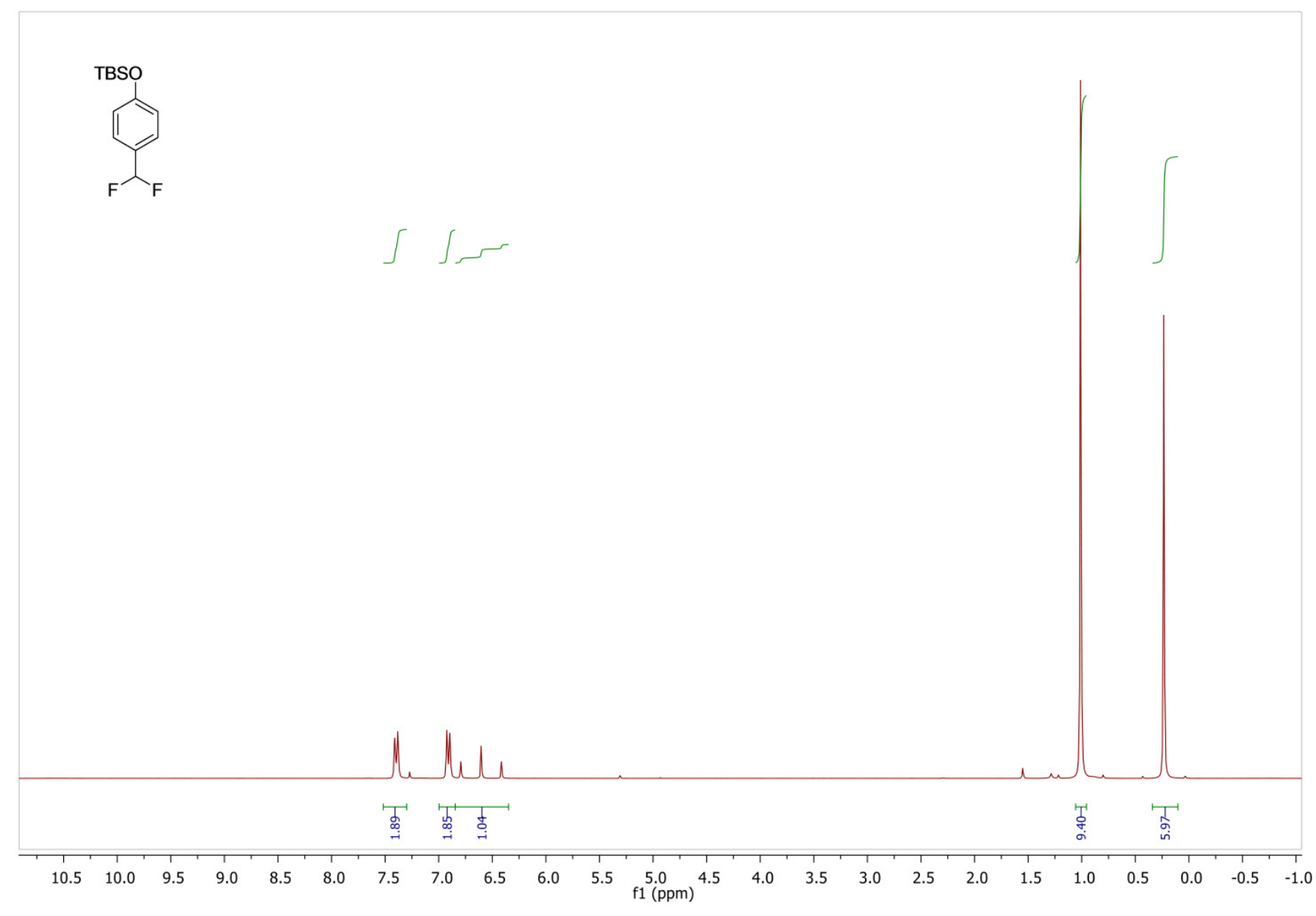

Figure 35. ${ }^{1} \mathrm{H}$ NMR spectra of compound 2 


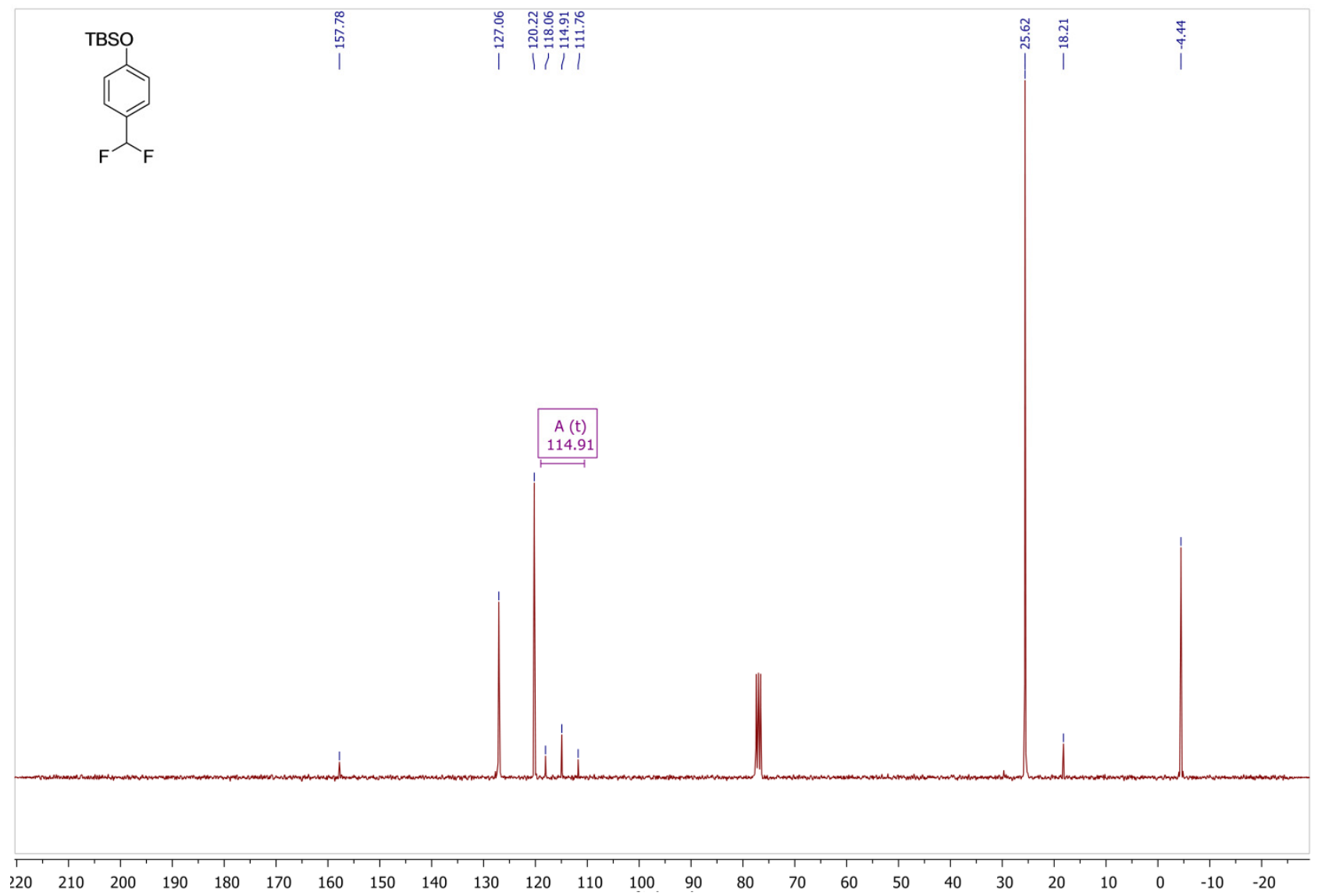

Figure 36. ${ }^{13} \mathrm{C}$ NMR spectra of compound 2 . 


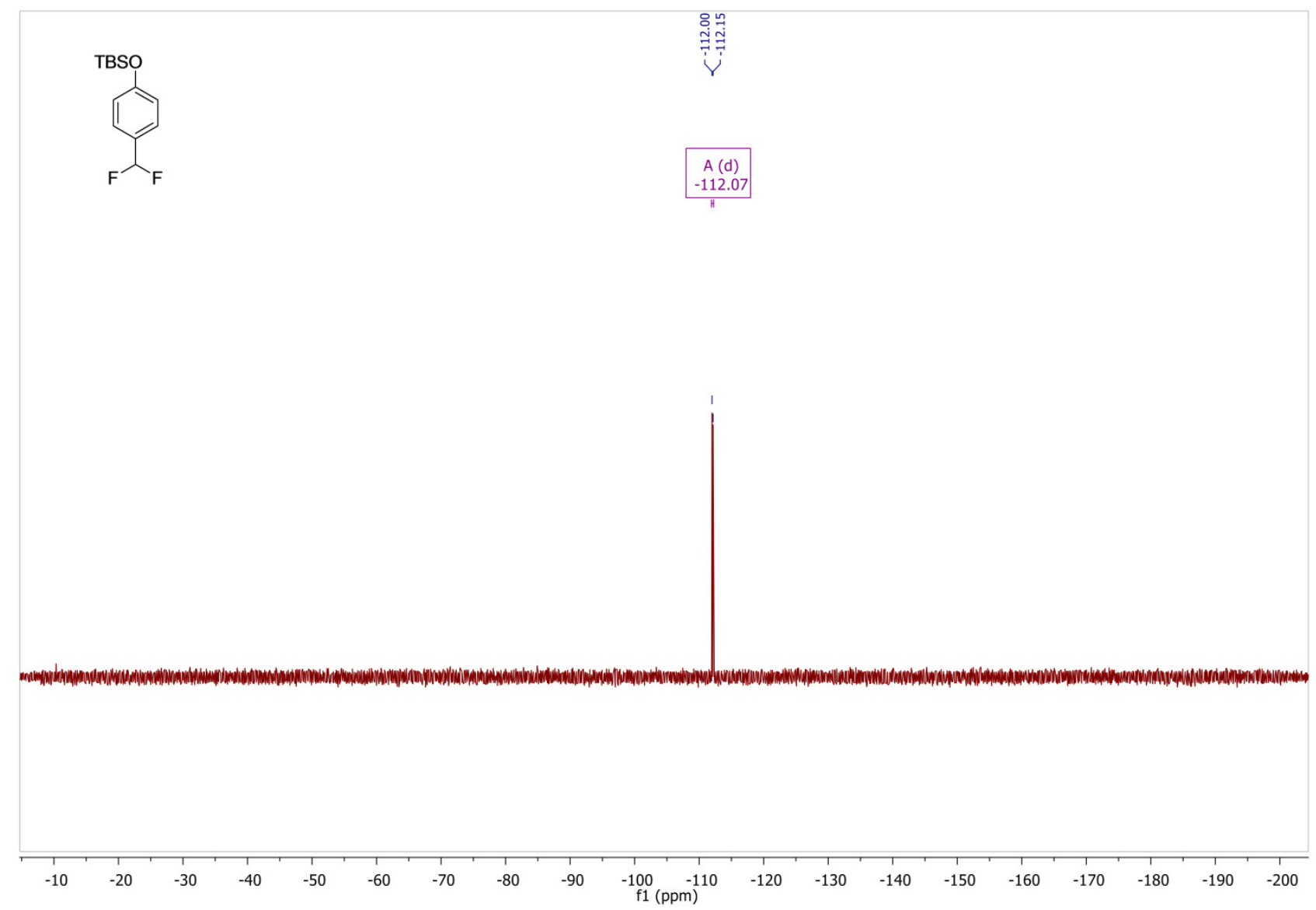

Figure 37. ${ }^{19} \mathrm{~F}$ NMR spectra of compound 2. 


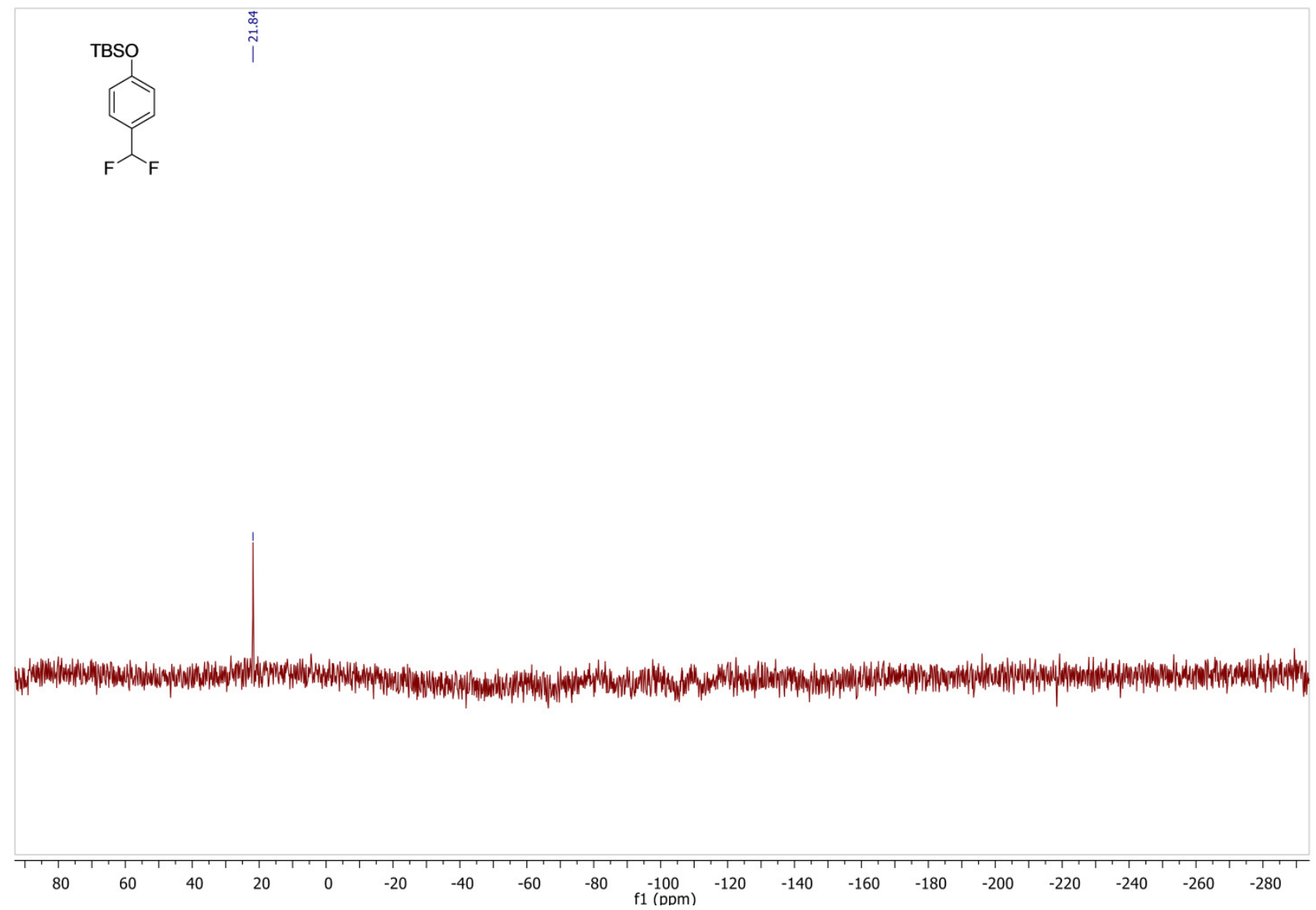

Figure 38. ${ }^{29} \mathrm{Si}$ NMR spectra of compound 2. 


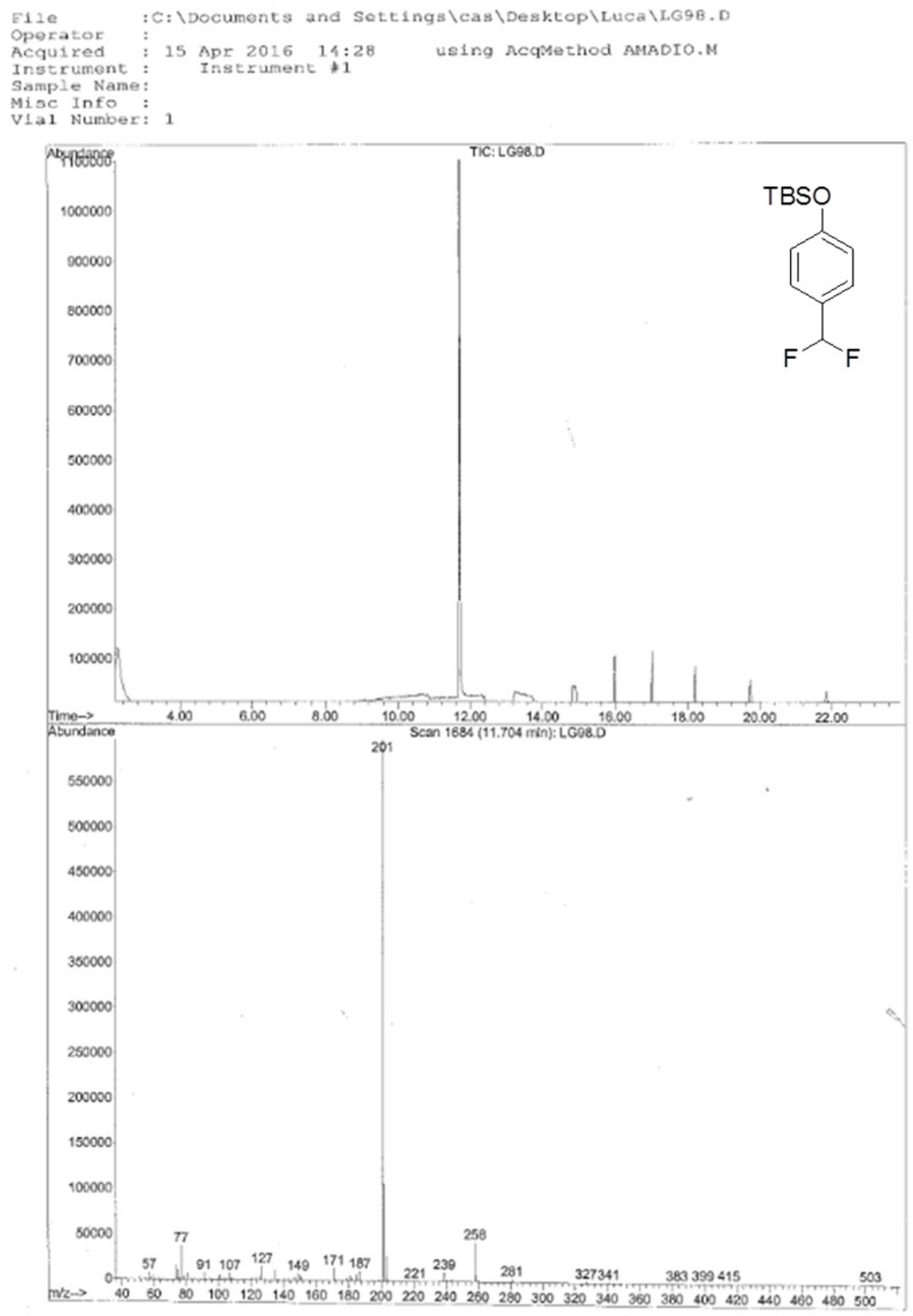

Figure 39. GCMS spectra of compound 2. 


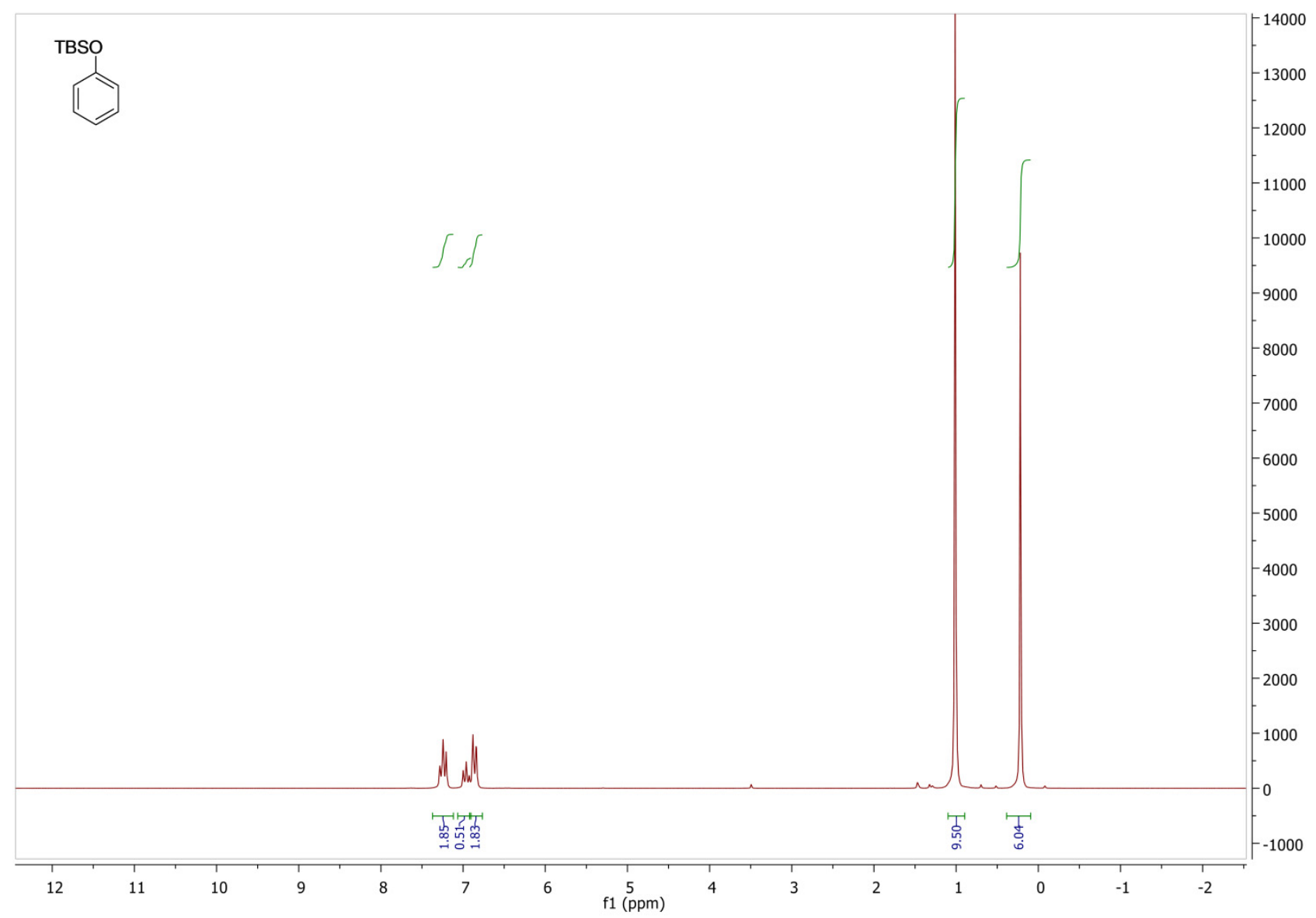

Figure 40. ${ }^{1} \mathrm{H}$ NMR spectra of compound 3. 


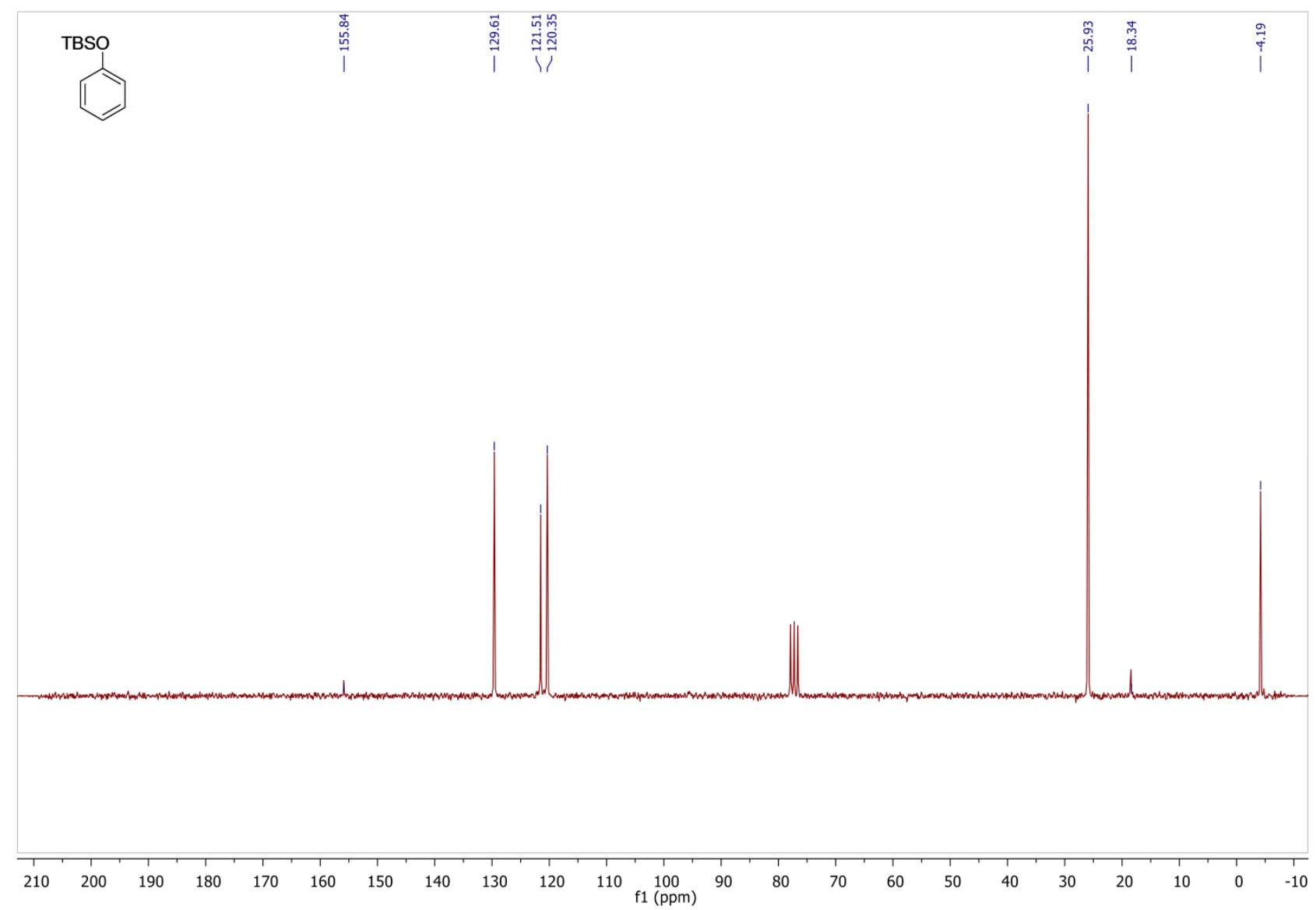

Figure 41. ${ }^{13} \mathrm{C}$ NMR spectra of compound 3 . 